\title{
Yournal of Cancer
}

Review

\section{Biological Markers in DCIS and Risk of Breast Recurrence: A Systematic Review}

\author{
Sara A. Lari and Henry M. Kuerer ${ }^{凶}$ \\ Department of Surgical Oncology, The University of Texas MD Anderson Cancer Center, Houston, TX, USA
}

$\square$ Corresponding author: Henry M. Kuerer, MD, PhD, FACS, Department of Surgical Oncology, DCIS Discovery Enterprise, Unit 1484, The University of Texas MD Anderson Cancer Center, 1400 Pressler Street, Houston, Texas 77030. Telephone: 713-745-5043, Fax: 713-792-4689, Email: hkuerer@mdanderson.org

(C) Ivyspring International Publisher. This is an open-access article distributed under the terms of the Creative Commons License (http://creativecommons.org/ licenses/by-nc-nd/3.0/). Reproduction is permitted for personal, noncommercial use, provided that the article is in whole, unmodified, and properly cited.

Received: 2011.04.07; Accepted: 2011.04.30; Published: 2011.05.01

\begin{abstract}
Understanding of the biology and clinical behavior of ductal carcinoma in situ (DCIS) is currently inadequate. The aim of this comprehensive review was to identify important molecular biological markers associated with DCIS and candidate markers associated with increased risk of ipsilateral recurrence after diagnosis of DCIS. A comprehensive systematic review was performed to identify studies published in the past 10 years that investigated biological markers in DCIS. To be included in this review, studies that investigated the rate of biological expression of markers had to report on at least 30 patients; studies that analyzed the recurrence risk associated with biomarker expression had to report on at least 50 patients. There were 6,252 patients altogether in our review. Biological markers evaluated included steroid receptors, proliferation markers, cell cycle regulation and apoptotic markers, angiogenesis-related proteins, epidermal growth factor receptor family receptors, extracellular matrix-related proteins, and COX-2. Although the studies in this review provide valuable preliminary information regarding the expression and prognostic significance of biomarkers in DCIS, common limitations of published studies (case-series, cohort, and case-control studies) were that they were limited to small patient cohorts in which the extent of surgery and use of radiotherapy or endocrine therapy varied from patient to patient, and variable methods of determining biomarker expression. These constraints made it difficult to interpret the absolute effect of expression of various biomarkers on risk of local recurrence. No prospective validation studies were identified. As the study of biomarkers are in their relative infancy in DCIS compared with invasive breast cancer, key significant prognostic and predictive markers associated with invasive breast cancer have not been adequately studied in DCIS. There is a critical need for prospective analyses of novel and other known breast cancer molecular markers in large cohorts of patient with DCIS to differentiate indolent from aggressive DCIS and better tailor the need and extent of current therapies.
\end{abstract}

Key words: Biological Markers, Ductal carcinoma in situ, DCIS, Breast Recurrence

\section{INTRODUCTION}

A diagnosis of ductal carcinoma in situ (DCIS) of the breast was rare before the 1980s; however, with the introduction of mammography, the incidence of DCIS grew dramatically. Currently, more than 60,000 patients are diagnosed with DCIS in the United States each year. For many years, mastectomy was the standard procedure to treat DCIS; however, since DCIS is a noninvasive and silent disease, 
breast-conserving therapy with or without radiotherapy is now considered sufficient and the accepted method to treat DCIS. A definitive goal in treating DCIS is to prevent ipsilateral invasive breast cancer recurrence as the mortality associated with a diagnosis of pure DCIS is less than 1-2\% [1]. About $5-30 \%$ of patients with DCIS treated with breast-conserving therapy with or without radiation experience an ipsilateral local recurrence, and about half of these recurrences are invasive. Clinicians are unable to predict the risk of local recurrence or progression to invasive breast cancer in patients with DCIS following their treatment, a major concern that needs to be addressed. Numerous studies have been conducted to address this concern, and in a few studies, investigators have concluded that several histopathologic characteristics of DCIS-lesion size, margin status, nuclear grade, architectural pattern, and presence of necrosis - are predictors of recurrence [1].

The U.S. National Cancer Institute has recently identified a critical need for investigation and validation of molecular factors to improve risk stratification of patients with DCIS, which will facilitate identification of the optimal therapy for each individual patient [2].

A molecular biological marker ("biomarker") is a molecular feature that is objectively measured and that serves as an indicator of a normal biological response, a pathogenic process, or the likelihood of response to an existing or novel pharmacologic therapy. In cancer, biomarkers may be used for disease detection, disease staging, monitoring of disease response to therapy, and prediction of patient prognosis [3]. A biomarker may be DNA or RNA based or a protein marker measured directly in tissues, serum, or other body fluids [3].

For DCIS, the optimal biomarker or combination of measured biomarkers would provide additional prognostic information beyond that provided by other clinical and pathologic factors established in the field as risk factors for local recurrence, such as lesion grade, lesion size, patient age, margin status, and use versus nonuse of adjuvant radiotherapy. The perfect biomarker or combination of biomarkers and/or clinical pathologic factors would establish which cases of DCIS were highly unlikely to ever be associated with progression to invasive breast cancer and thus which patients needed no further therapy. Biomarker expression might also be useful in individualizing therapy for DCIS with respect to the need for local excision versus mastectomy or the need for adjuvant radiotherapy.

Validation of cancer biomarkers is complex and must be thorough if the marker is to be used in patient care [4-6]. The aim of this comprehensive review was to identify important biomarkers associated with DCIS and candidate biomarkers associated with increased risk of ipsilateral recurrence after diagnosis of DCIS.

\section{METHODS}

A comprehensive search of the MEDLINE and Cochrane databases was performed on February 4, 2011. Search terms included the U.S. National Library of Medicine's Medical Subject Headings ductal carcinoma in situ, in situ breast cancer, intraductal carcinoma, stage 0 breast cancer, and DCIS. Additional search terms included estrogen receptor, progesterone receptor, androgen receptor, Ki-67, cyclin D1, cyclin $A$, cyclin $E$, $p 16, p 21, p 27, p 53, B c l-2, B a x$, survivin, $c-m y c, R b, V E G F$, HPR1, HER1, HER2, HER3, HER4, CD10, SPARC and COX-2 (Table 1). A total of 622 studies were identified on biological markers in DCIS published in November 2000 or later. One additional significant study published in 1998 and referenced in other studies included in the review was also included [7]. The following types of studies were excluded: in vitro studies; studies involving only animals; case reports; and studies reporting on patients with concurrent invasive breast cancer or non-breast malignancies. Studies that investigated the rate of biological expression of markers had to report on at least 30 patients, and studies that analyzed the recurrence risk associated with biomarker expression had to report on at least 50 patients. There were 6,252 patients altogether in our review.

\section{RESULTS}

Biomarker expression rates for different categories of biomarkers and notes on how expression rates were derived are presented in Tables 2-8. Information on the relationship between biomarker expression and the risk of ipsilateral recurrence following surgery for DCIS is presented in Table 9. Table 9 lists the year published, the number of patients in the study, the type of surgery performed, whether post-lumpectomy radiotherapy was given, the median follow-up time, whether endocrine therapy was utilized, and a synopsis of whether the biomarker studied was associated with an increased risk of local recurrence.

\section{Steroid Receptors}

\section{Estrogen Receptor}

Estrogen receptor (ER) was one of the first biological markers to be studied in depth, and today ER is one of the most valuable markers in breast cancer. ER status in patients with breast cancer predicts re- 
sponse to endocrine therapy. Among the 36 studies in our comprehensive review that examined ER expression rate in DCIS, the mean ER expression rate was $68.7 \%$ (range: $49-96.6 \%$, Table 2 ).

Numerous studies revealed ER expression to be inversely related to the nuclear grade of DCIS: ER expression was higher in well-differentiated lesions than in poorly differentiated lesions [8-15]. One study revealed that ER expression was more common in cribriform DCIS than in other DCIS subtypes [7]. Similarly, another study revealed that ER expression was more common in papillary, solid, and cribriform DCIS than in micropapillary and comedocarcinoma DCIS [9].

Many investigators studied the relationship between ER and other biological markers. Several studies revealed ER to be inversely correlated with HER-2/ neu (HER2) expression [7, 9, 13, 16-18]. One study revealed that ER expression was inversely correlated with p53 expression [7]. A few studies revealed ER expression to be positively associated with high Bcl-2 expression $[7,12,16]$. One study reported a significant correlation between ER negativity and cyclooxygenase-2 (COX-2) positivity [19]; however, another study did not find a significant correlation between ER and COX-2 [20]. Kulkarni et al reported several significant associations between ER and other markers-for instance, progesterone receptor (PR), Cyclin D1, p53, and p21 [21]. Altintas et al reported that lesions with high proliferative activity were more likely to be ER negative [15].

\section{ER Expression and Risk of Local Recurrence}

We identified 16 studies (2,470 total patients) that evaluated the relationship between ER expression and risk of local recurrence (Table 9). Four of these studies revealed an association between ER-negative DCIS and risk of local recurrence [16, 22-24]. In the first study, a nested case-control study by Provenzano et al, the investigators compared 53 patients with DCIS who had a subsequent local recurrence to 42 age- and date- of-diagnosis-matched control subjects with DCIS who did not have a recurrence [22]. Patients in the series had breast-conserving surgery with $(n=10)$ or without adjuvant radiotherapy $(n=85)$. Patients with subsequent local recurrence were more likely than those without recurrence to have ER-negative disease ( $62 \%$ vs. $35 \%$; OR: $0.2 ; P=0.01$, Table 9) [22].

In the second study that found a relationship between ER-negative DCIS and risk of local recurrence, another nested case-control study, Kerlikowske et al evaluated biomarker expression and risk of local recurrence among 329 patients with DCIS who were all treated with wide local excision without subsequent radiotherapy. The authors selected tissues to be studied for biomarker expression from 72 women who had a subsequent invasive cancer event, 71 women who had a subsequent DCIS event, and 186 randomly selected women who served as control subjects who did not have a subsequent tumor event [24]. This nested case-control study had a median follow-up time of 8.2 years. According to the univariate analysis, patients with a subsequent DCIS event were more likely than those without a subsequent tumor event to have ER-negative disease $(31 \%$ vs. $20 \%$, Table 9). ER-negative status was individually associated with DCIS recurrence. In addition, ER-negative status combined with either HER2 expression or Ki-67 expression was associated with DCIS recurrence. Similar results were observed in the multivariate analysis. Patients with DCIS recurrence were more likely to exhibit the phenotype ER-HER2+Ki-67+, and this phenotype was a predictor of DCIS recurrence (hazard ratio: 5.8; 95\% confidence interval [CI]: 2.4-14, Table 9). In patients who developed a subsequent invasive tumor, the investigators did not find ER to be a predictor of recurrence either individually or in combination with other markers in a phenotype [24]. This study by Kerlikowske et al is one of the largest and arguably one of the most important studies in the field. This study by Kerlikowske et al is valuable because it allows clinicians to study a group of patients who all underwent the identical therapy for DCIS - in this case local excision alone without radiotherapy. Overall, $28 \%$ of the patients had a local-regional recurrence. This high rate of recurrence may be related to the fact that $45-61 \%$ of patients in the study had positive margins or uncertain margin status [24]. Obtaining definitive negative margins is now a well-known, accepted prerequisite for breast-conserving therapy [1], and this situation illustrates the complexity of interpreting results and the potential clinical value of these types of biomarker studies for present day therapy of DCIS.

In the third study that found a relationship between ER-negative DCIS and risk of local recurrence, Roka et al evaluated 132 patients with DCIS treated with breast-conserving surgery without $(n=33)$ or with whole-breast radiotherapy $(\mathrm{n}=99)$ and found that patients with ER-negative DCIS were more likely than those with ER-positive DCIS to have a local recurrence $(12.2 \%$ vs. $3.7 \%$, Table 9$)$ [23]. This study provides clinically useful information in that it gives an absolute difference between the rates of local recurrence in patients with ER-negative and ER-positive DCIS treated with surgery and radiotherapy: about $8.5 \%$. 
Ringberg et al investigated 187 patients with DCIS who underwent breast-conserving therapy with $(n=66)$ or without $(n=121)$ radiotherapy. In the group of patients who did not receive radiotherapy, 31 patients had a recurrence. The authors used principal components analysis to evaluate a cell biological index that included ER and PR negativity, overexpression of HER2, low Bcl-2 expression, accumulation of p53, nondiploidy, and high Ki-67 expression. According to the multivariate analysis, the combination of ER-negative DCIS and the biological markers in the index was a strong predictor of local-regional recurrence (relative risk: 1.3; 95\% CI: 1.0-1.6, Table 9) [16].

Zhou et al [25] examined the relationship between triple-negative DCIS (negative for ER, PR, and HER2; also known as basal-like breast cancer) and risk of local recurrence. This study included 392 patients, approximately half of whom received adjuvant radiotherapy. Of the 392 patients, 42 patients had an in situ recurrence, and 34 had an invasive recurrence. The authors compared the 32 patients with triple-negative DCIS with the 360 patients with other phenotypes and found that patients with basal-like DCIS had a higher risk of local recurrence. However, this difference did not reach statistical significance. This study illustrates additional barriers to determining the effect of biomarker expression on local recurrence, including small number of patients and inconsistent use of adjuvant treatments (e.g., radiotherapy), which can confound results.

\section{ER Expression and Response to Therapy}

A predictive biomarker is a marker that can predict the response to a specific therapy. For invasive breast cancer, the presence of ER expression and the degree of ER expression have unequivocally been shown to predict response to tamoxifen, which blocks $\mathrm{ER}$, and aromatase inhibitors, which prevent production of estrogen. In women with ER expression, ER has been demonstrated to affect the expression of other relevant biomarkers and lead to increased survival and decreased recurrence risk in women taking tamoxifen or aromatase inhibitors compared to women not taking these drugs [26]. In contrast, no demonstrative effect of tamoxifen or aromatase inhibitors is seen in patients whose invasive tumors lack ER expression.

For DCIS, we found four clinical trials that may shed light on the value of ER for predicting response to tamoxifen and aromatase inhibitors. The first two studies were landmark phase III trials in which patients with DCIS were randomized to tamoxifen or placebo after local excision of DCIS. The first, the UK/ANZ DCIS trial, involved 1,701 patients and had an unusual randomization scheme involving the use of adjuvant tamoxifen and radiotherapy with elective decision to withhold or provide one of these treatments [27]. The median follow-up time was 12.7 years. Although tamoxifen significantly reduced the incidence of all new breast events $(P<0.0001)$, the absolute differences between rates of new breast cancer events in women randomized to tamoxifen and no tamoxifen were small. Patients randomized to tamoxifen had a $3.5 \%$ absolute 10 -year reduction in the risk of ipsilateral DCIS recurrence, no change in the risk of ipsilateral invasive breast cancer, and a $2.3 \%$ absolute 10 -year reduction in the risk of new contralateral breast cancer.

The second landmark phase III trial was the National Surgical Adjuvant Breast and Bowel Project (NSABP) B-24 clinical trial, which included 1,804 women, and in which tamoxifen was also investigated among patients receiving radiotherapy [28]. At a median follow-up time of 12 years, there were very small but statistically significant absolute reductions in rates of breast cancer events among patients randomized to tamoxifen versus placebo (a $2.4 \%$ reduction in the risk of ipsilateral invasive breast cancer recurrence, no change in the risk of ipsilateral DCIS recurrence, and a $3.2 \%$ reduction in the risk of contralateral breast cancer events). An important caveat in interpreting these data is that in both the UK/ANZ and NSABP B-24 trials, patients were not selected to receive tamoxifen on the basis of ER positivity. The magnitude of benefit might have been higher if only patients with ER-positive DCIS had been enrolled. Nevertheless, taken together, the results of these two trials suggest that ER appears to be a weakly predictive biomarker for effecting local recurrence following treatment for DCIS.

The third pivotal trial implicating ER as a predictive biomarker for endocrine manipulation of ER-positive DCIS was reported by Chen et al [29]. This small study, involving just 23 patients, was undertaken to investigate whether neoadjuvant (administered before surgery) endocrine therapy resulted in detectable histologic alterations. In order to determine whether such treatment results in detectable histologic alterations, the authors compared the pathologic and biomarker changes in DCIS following neoadjuvant endocrine therapy (that is, before surgery) to a group of patients who did not undergo preoperative anti-estrogenic treatment. Premenopausal women were treated with tamoxifen, and postmenopausal women were treated with letrozole. Pathologic markers of proliferation, inflammation, and apoptosis were evaluated at baseline and at 3 months. Following treatment, predominant morphologic changes in- 
cluded increased multinucleated histiocytes and degenerated cells, a decrease in expression of the proliferation marker $\mathrm{Ki}-67$, and immune infiltration into the lesions consistent with a treatment effect. This study was significant because of its novel clinical trial design, the so-called "window study design," which allows investigators to test potentially promising agents for DCIS and immediately assess biological response when the patient undergoes surgery $[29,30]$.

The fourth important trial implicating ER as a predictor of response to endocrine therapy was another window study, by Bundred et al. These authors randomized 90 postmenopausal patients with ER-positive DCIS to one of the following treatments for 2 weeks before surgery: exemestane, an aromatase inhibitor; celecoxib, a COX-2 inhibitor; exemestane and celecoxib; or placebo [30]. Exemestane significantly reduced proliferation compared with placebo; the median reduction was $9 \%$. The effect of exemestane on proliferation was seen regardless of grade, HER2 expression, or PR expression. Celecoxib had no effect on proliferation or apoptosis either when the drug was administered alone or when it was administered in combination with exemestane. Thus, pharmacologic endocrine ablation with exemestane in postmenopausal patients with ER-positive DCIS resulted in a significant reduction in proliferation of cancer cells in the short term. However, the clinical utility of aromatase inhibitors remains to be determined from studies to be reported utilizing this class of drugs in the adjuvant setting [1].

\section{Progesterone Receptor}

PR is considered to be as important as ER in invasive breast cancer. In invasive breast cancer, expression of PR is weakly prognostic with respect to disease-free survival and also a predictor of response to endocrine therapy. Among the 28 studies in our review that examined PR expression rate in DCIS, the mean PR expression rate was 59.6\% (range: $40-83.3 \%$, Table 2). As with ER, an inverse relationship was observed between PR expression and nuclear grade. Patients with high-grade DCIS were less likely than patients with non-high-grade DCIS to have PR-positive disease [8-10, 12, 14, 15]. One study revealed that PR expression was more common in cribriform DCIS and noncomedo DCIS than in other subtypes [7]. Another study revealed that PR expression was more common in papillary, solid, cribriform, micropapillary, and comedocarcinoma subtypes than in other subtypes [9].

A majority of the studies included in our review investigated the relationship between PR and other biological markers. A direct positive relationship was observed between PR expression and ER expression $[7,9,21]$. Also, a positive relationship was observed between PR expression and Bcl-2 expression [7, 16, 22]. One study revealed a significant correlation between PR status and p27 status [31]. Several studies reported an inverse relationship between PR expression and HER2 expression [7, 9, 12, 16, 17, 21]. A few studies revealed an inverse relationship between PR expression and p53 expression $[7,16]$. In addition, an inverse relationship was observed between PR expression and Ki-67 expression $[15,16]$.

Thirteen studies (2,051 total patients) in our review evaluated the relationship between PR expression and risk of recurrence, and only two of these studies revealed a significant correlation. In a nested case-control study, Provenzano et al found that PR negativity was independently associated with risk of local-regional recurrence. These authors compared tissues from patients who subsequently developed ipsilateral recurrence (cases) with those from patients who did not develop a recurrence (controls). Patients who developed a local-regional recurrence were more likely than controls to have PR-negative disease $(63 \%$ vs. 34\%, Table 9) [22]. As mentioned previously, Ringberg et al found that a cell biological index that included ER and PR negativity, overexpression of HER2, low Bcl-2 expression, accumulation of p53, nondiploidy, and high Ki-67 expression was a strong predictor of recurrence [16].

\section{Androgen Receptor}

Breast cancer is known to be a hormonally dependent carcinoma. Many immunohistochemical studies conducted to date have revealed androgen receptor (AR) to be often co-expressed with ER and PR in breast tumors, but only a few studies have examined the role and significance of AR in breast cancer etiology and prognosis [32,33]. Among the four studies in our review that examined AR expression rate in DCIS, the mean AR expression rate was $65.8 \%$ (range: $37-81 \%$, Table 2). Hanley et al found that unlike expression of the other steroid receptors, ER and PR, expression of AR was slightly higher in high-grade DCIS than in non-high-grade DCIS, although the difference was not significant ( $93 \%$ vs. $89 \%$ ) [8]. Hanley et al studied patterns of co-expression of ER and PR with AR. These authors reported that $87 \%$ of non-high-grade DCIS lesions compared with 30\% of high-grade DCIS lesions expressed both AR and ER. The co-expression pattern was similar for PR [8]. $\mathrm{Yu}$ et al reported similar findings with respect to co-expression of AR with ER $(P<0.001)$ and PR $(P=0.035)$ [33].

There were only two studies that investigated 
the relationship between $\mathrm{AR}$ expression and risk of recurrence. Provenzano et al found that AR expression was not a predictor of local recurrence of DCIS [22]. Another study that we identified during our initial search did not meet our selection criteria because too few patients were studied; only 34 patients with DCIS were investigated [33].

\section{Proliferation marker-Ki-67}

Information on expression of Ki-67 in DCIS is presented in Table 3. The nuclear antigen Ki-67 is commonly used to assess the proliferation rate of breast cancer tumors, which is a key element of progression of the disease [34]. Our review included 16 studies that reported Ki-67 expression rates in DCIS (Table 3). Barnes et al. reported a median expression of Ki-67 in DCIS as $10.9-15.5 \%$ (Table 3) [35]. Kuerer et al reported that the mean ( \pm standard deviation) percentage of cells staining for Ki-67 was $44.29 \pm$ $3.42 \%$ (Table 3). This expression rate is likely high because all the patients in this series had HER2-positive DCIS, and were more likely to have high-grade lesions [18]. Bundred et al reported that the median percentage of cells staining for Ki-67 at baseline was $13.5-20.7 \%$ in the various subgroups in a randomized trial of aromatase-inhibitor therapy in patients with ER-positive DCIS (Table 3) [30].

A few studies revealed high proliferative activity to be comedo DCIS than in DCIS with other architectural patterns $[7,16]$. In addition, high proliferative activity was associated with high-grade versus non-high-grade DCIS lesions $[12,16,36]$.

Three of the nine studies (1,365 total patients) in our review that evaluated the relationship between $\mathrm{Ki}-67$ expression and the risk of local recurrence concluded that Ki-67 was not significantly associated with disease recurrence (Table 9). The remaining studies showed that Ki-67 was a predictor of local recurrence, either independently or in combination with other factors. Barnes et al, by means of multivariate analysis, reported that $\mathrm{Ki}-67$ was an independent predictor of recurrence (Odds ratio: 1.03; 95\% CI: $1.00-1.06 ; P=0.038$, Table 9). Patients in this study who had had a recurrence had significantly higher median proliferative activity than patients who had not had a recurrence $(15.5 \%$ vs. $10.9 \%, P=0.005)$ [35]. In a similar study conducted by Wilson et al, by means of univariate analysis, patients with recurrence were more likely to exhibit high proliferative activity than patients without recurrence $(71.4 \%$ vs. $42.2 \%$, $P=0.006)$. However, in the multivariate analysis, Ki-67 was not found to be a predictor of local recurrence. [37]. Kerlikowske et al found that high Ki-67 expression (more than $10 \%$ of tumor cells stained) was indi- vidually associated with recurrence of DCIS in the univariate analysis, but, Ki-67 was not individually associated with subsequent invasive tumor. However, the phenotype $\mathrm{Ki}-67+\mathrm{p} 16+$ and the phenotype Ki-67+p16+COX-2+ were associated with subsequent invasive tumor. Ki-67 was individually associated with DCIS recurrence, and the phenotypes Ki-67+ER- , $\mathrm{Ki}-67+\mathrm{p} 16+$, and $\mathrm{Ki}-67+\mathrm{p} 16+\mathrm{COX}-2+$ were also associated with DCIS recurrence. In the multivariate analysis, the Ki-67+p16+COX-2+ phenotype was a strong predictor of subsequent invasive recurrence (HR: 2.2; 95\% CI: 1.1-4.5, Table 9). Ki-67+p16+COX-2(HR: 3.7; 95\% CI: 1.7-7.9, Table 9) and ER-HER2+Ki-67+ (HR: 5.8; 95\% CI: 2.4-14, Table 9) were two phenotypes that were strong predictors of subsequent DCIS recurrence [24].

\section{Cell Cycle Regulation and Apoptotic Markers}

\section{Cyclin DI}

Cyclin D1 is one of the many proteins involved in cell cycle regulation, specifically regulation of the mid-G1 phase. It is also responsible for regulating cyclin-dependent kinases [38]. Overexpression of cyclin D1 is commonly seen in breast cancer, but it has also been identified in many other tumors [39, 40]. Among the six studies in our review that examined cyclin D1 expression rate in DCIS, the mean cyclin D1 expression rate was $55.9 \%$ (range: $37-70.6 \%$, Table 4 ).

$\mathrm{Oh}$ et al reported a significant correlation between cyclin D1 expression and ER expression [41]. However, Lebeau et al or Millar et al did not find an association between overexpression of cyclin D1 and expression of ER and PR [12, 31].

In our comprehensive search, we identified five studies (443 total patients) that investigated the prognostic significance of cyclin D1. Jirström et al found cyclin D1 to be strongly and inversely related with ipsilateral local recurrence. Patients with low cyclin D1 fraction had a higher risk of ipsilateral local recurrence than patients with high cyclin D1 fraction ( $32.3 \%$ vs. $18.2 \%, P=0.002$, Table 9) [42]. Findings from the other four studies indicated no significant correlation between cyclin D1 and risk of local-regional recurrence $[21,31,38,43]$.

\section{Cyclin A}

Cyclin A, like cyclin D1, is one of the proteins in the cell cycle responsible for regulating cyclin-dependent kinases [38]. We found only two studies that investigated the role and significance of cyclin A in DCIS. Millar et al reported that $35 \%$ of the DCIS lesions in their study expressed cyclin A (Table 4), and Chasle et al did not report an expression rate in their study. These authors found no association 
between cyclin A expression and expression of ER or PR or with any histologic features. However, Chasle et al found cyclin A expression to be significantly higher in comedo DCIS than in noncomedo DCIS. In the same study, the investigators found cyclin A expression to be positively correlated with expression of two other biological markers, Ki-67 and p21 [38]. Overall, the investigators did not observe cyclin A to be an independent predictor of local-regional recurrence; however, when they studied global proliferation factor, a combination of Ki-67 and cyclin A, they found this factor to be correlated with local recurrence [38].

\section{Cyclin E}

Like cyclin D1 and cyclin A, cyclin E interacts with cyclin-dependent kinases in the late-G1 phase of the cell cycle [44]. We identified one study that investigated the relationship between cyclin E expression and recurrence in DCIS. Jirström et al reported that approximately $25 \%$ of the 92 cases of DCIS in their study had high cyclin E expression [42] (Table 9). In the same study, the investigators found that cyclin E was not an independent predictor of disease recurrence [42].

\section{PI6}

P16 is a tumor suppressor protein that regulates cellular proliferation and growth by acting as a cyclin-dependent kinase 4 inhibitor. In the three studies we identified that examined p16 expression in DCIS, the mean p16 expression rate in DCIS was 33.7\% (range: $28-39.3 \%$, Table 4). Gauthier et al did not observe associations between p16 expression and any histologic factors or hormone receptors [45], and the other two studies did not look for associations between p16 expression and other factors.

We identified three studies (576 total patients) that investigated the effect of p16 expression on local recurrence of DCIS. Jirström et al found that p16 was not an independent risk factor for recurrence [42]. Interestingly, Gauthier et al reported that among patients with high p16 expression and high COX-2 expression, patients with high proliferative activity were more likely to have a local-regional recurrence than patients with low proliferative activity [45]. In a follow-up study by the same investigators, Kerlikowske et al, by means of univariate analysis, found p16 to be the only individual marker associated with subsequent invasive recurrence ( $57 \%$ vs. $30 \%$, HR: 2.3 , Table 9). p16 was also associated with subsequent invasive recurrence when it was combined with two other biological markers, Ki-67 expression and COX-2 expression. p16 was also associated with subsequent
DCIS recurrence when it was combined with Ki-67 expression and lack of COX-2 expression. In the multivariate analysis, the p16+COX-2+Ki-67+ triple-positive phenotype was a strong predictor of subsequent invasive recurrence (HR: 2.2; 95\% CI: 1.1-4.5, Table 9), and the p16+COX-2-Ki-67+ phenotype was a predictor of subsequent DCIS recurrence (HR: 3.7; 95\% CI: 2.4-14, Table 9) [24].

\section{P2I}

P21 is an important protein that plays a role in cell cycle arrest. Studies have shown that p21 can either be a downstream target of p53 or can induce cell arrest independently of p53 [12, 46]. Among the six studies we identified that examined p21 expression rate in DCIS, the mean p21 expression rate was 53.1\% (range: 29.6-76\%, Table 4). Lebeau et al reported p21 to be significantly associated with nuclear grade and Van Nuys prognostic index; however, Oh et al reported p21-positive DCIS to be associated with well-differentiated histologic grade $[12,41]$. With respect to clinicopathological factors, Oh et al also found that p21 expression was associated with noncomedo DCIS and tumors without necrosis [41]. When Lebeau et al studied the relationship between p21 and other biological markers, they found no correlation between p21 expression and p53 expression; however, p21 expression was significantly associated with expression of epidermal growth factor receptor and overexpression of HER2. In addition, p21 expression was correlated with cyclin D1 expression, but only in HER2-positive cases [12]. Kulkarni et al also investigated the relationship between p21 and other biological markers, and they found that p21 expression was significantly correlated with ER and cyclin D1 positivity [21]. Oh et al found p21 expression to be significantly positively correlated with ER expression and significantly inversely correlated with p53 expression [41]. Cornfield et al found no correlation between p21 and the other biological markers tested in their study (ER, PR, HER2, Ki-67, and Bcl-2) [46].

Four studies (365 total patients) in our comprehensive search examined the effect of p21 expression on local recurrence in DCIS. Only one study identified p21 as an independent predictor of recurrence. Provenzano et al reported that patients with local-regional recurrence were more likely than those without recurrence to have p21-positive disease (54\% vs. $15 \%$, Odds ratio: $6.0 ; P=0.01$, Table 9) [22].

\section{P27}

P27 is a cyclin-dependent kinase inhibitor, and it also plays an important role in growth signaling. In recent breast cancer studies, loss of p27 has been as- 
sociated with poor patient outcome [31, 47]. Among the three studies in our review that examined p27 expression rate in DCIS, the mean p27 expression rate was $56.8 \%$ (range: $46.9-68.5 \%$, Table 4 ). Jirström et al studied the associations between p27 and other biological markers, and they found p27 expression to be significantly correlated with p16 and cyclin D1 expression [42]. Millar et al and $\mathrm{Oh}$ et al observed p27 status to be significantly associated with cyclin D1 and ER status [31, 41]. Millar et al also found a significant association between p27 status and PR status [31]. In the same study, no association was observed between p27 positivity and cyclin A positivity or between cyclin A positivity and cyclin D1 positivity. Millar et al and Oh et al found no correlation between p27 and clinicopathological factors [31, 41]. In our comprehensive search, we found only two studies (237 total patients) that investigated the relationship between p27 expression and risk of local recurrence in DCIS. Both studies showed that p27 was not a predictor of local recurrence (Table 9).

\section{P53}

P53, a tumor suppressor gene, is responsible for apoptosis in the cell cycle. A mutation of p53 can compromise its function. P53 mutations are common in many cancers and occur in approximately $20 \%$ of breast carcinomas [43]. Among the 17 studies in our review that examined $\mathrm{p} 53$ expression rate in DCIS, the mean $\mathrm{p} 53$ expression rate was $41.4 \%$ (range: $11.3-88 \%$, Table 4). Two studies revealed p53 expression to be more likely in DCIS of comedo type [7, 48]. Other studies showed p53 expression to be correlated with high tumor grade $[36,48]$. Hieken et al also found that p53 was significantly associated with tumor grade and the presence of necrosis [48].

Several studies investigated the relationship between p53 and other biological markers. Ringberg et al reported p53 expression to be positively correlated with expression of ER, PR, HER2, and Bcl-2; however, Lebeau et al did not find p53 to be associated with either ER or PR $[12,16]$. Lebeau et al also noted a correlation between p53 expression and lack of expression of cyclin D1 [12].

We found ten studies (1,355 total patients) that looked at the relationship between p53 expression and local recurrence; only three of these studies showed an association. Ringberg et al used principal components analysis to evaluate a cell biological index that included ER and PR negativity, overexpression of HER2, low Bcl-2 expression, accumulation of p53, nondiploidy, and high Ki-67 expression. P53 when combined with these biological markers was a predictor of local-regional recurrence [16]. The specific rates of local recurrence associated with particular marker phenotypes were not discernible from the published report; however, the overall rate of recurrence was $25.6 \%$ among 121 patients treated with breast-conserving surgery without radiotherapy. Hieken et al reported that DCIS that recurred was more likely than DCIS that did not recur to exhibit strong p53 expression (63\% vs. $24 \%$, Table 9) [48]. Similarly, de Roos et al reported p53 expression to be an independent predictor of local recurrence (HR: 3.0, 95\% CI: 1.1-8.2, $P=0.036$, Table 9) [43].

\section{$\mathrm{BCl}-2$}

$\mathrm{Bcl}-2$ is one of the apoptosis regulator proteins. A deregulation in apoptosis due to imbalances in Bcl-2 expression has been associated with the pathogenesis of breast cancer [49]. Bcl-2 has been shown to be an independent prognostic biomarker in early-stage breast cancer and nasopharyngeal carcinoma [50, 51]. Among the six studies in our review that examined Bcl-2 expression rate in DCIS, the mean expression rate of Bcl-2 in DCIS among six reported studies was $55.4 \%$ (range: $48-58.8 \%$, Table 4 ). Warnberg et al found a higher expression of $\mathrm{Bcl}-2$ in well-differentiated lesions than in poorly differentiated lesions [36]. Several investigators studied the relationship between $\mathrm{Bcl}-2$ and other biological markers. Ringberg et al and Provenzano et al observed a positive association between Bcl-2 expression and expression of ER and PR [16, 22]. Jirström et al also observed a significant negative association between Bcl-2 expression and overexpression of HER2 [42].

We identified three studies (433 total patients) that investigated the association between Bcl-2 expression and risk of local-regional recurrence in DCIS. Cornfield et al found that Bcl-2 expression was not an independent predictor of local recurrence [46]. However, Provenzano et al found that DCIS that recurred was more likely than DCIS that did not recur to be Bcl-2 negative ( $66 \%$ vs. $26 \%$, respectively, Table 9) [22].

Bax

Bax is another protein that plays a role in promoting apoptosis [52]. In gastric carcinoma, colorectal, and pancreatic cancer, negative Bax expression has been shown to be a prognostic predictor [53]. According to Okumura et al, the rate of expression of Bax in DCIS was 71.2\% (Table 4) [52]. Bax is one of the less studied proteins in DCIS; we were unable to identify studies that investigated the significance of Bax expression in terms of local recurrence of DCIS. 


\section{Survivin}

Survivin is another important protein in the cell cycle, responsible for cell cycle regulation and inhibition of apoptosis [52]. Okumura reported an expression rate of survivin in DCIS of $55.8 \%$ (Table 4) [52]. Barnes et al reported the expression of survivin according to different staining: nuclear staining, 10\%; cytoplasmic staining, 29\%; and cytoplasmic and nuclear staining, 29\% [54]. Barnes et al reported no significant correlations between survivin and clinicopathological factors. We identified one study that investigated the recurrence risk associated with survivin [54]. In this study, patients with recurrence were more likely than those without recurrence to have co-expression of COX-2 and cytoplasmic survivin (70\% vs. $41 \%$, Table 9) [54].

\section{C-myc}

C-myc is a proto-oncogene that is known to play a role in proliferation, malignant transformation, and apoptosis. Although c-myc has been associated with poor prognosis in invasive breast cancer, few studies have evaluated c-myc expression levels in DCIS [55]. Altintas et al reported that the expression rate of c-myc in DCIS was 60\% (Table 4) [15]. In the same study, Altintas et al found that c-myc was not a predictor of local recurrence of DCIS (Table 9).

\section{Retinoblastoma}

Retinoblastoma $(\mathrm{Rb})$ is a tumor suppressor protein that plays an important role in regulating cell growth. Okumura et al reported that the expression rate of $\mathrm{Rb}$ in DCIS was $68.6 \%$. In the same study, the investigators found no significant difference in rates of $\mathrm{Rb}$ expression between pure DCIS and DCIS with microinvasion [52]. Few studies have evaluated $\mathrm{Rb}$ expression levels in DCIS, and no studies investigating the relationship between $\mathrm{Rb}$ expression rate and local recurrence of DCIS met our selection criteria.

\section{Angiogenesis-Related Proteins}

\section{Vascular endothelial growth factor}

Vascular endothelial growth factor (VEGF) is one of the most potent angiogenic factors. It acts as a mitogen for endothelial cells and also increases vascular permeability [48]. Our review included two studies that investigated the expression rate of VEGF in DCIS. The mean value was $89.9 \%$ (rates in the two studies were $86.0 \%$ and $93.8 \%$, Table 5). No studies in our comprehensive search found VEGF to be correlated with clinicopathological parameters. One study investigated the relationship between VEGF and other biological markers. The investigators found VEGF expression to be significantly associated with COX-2 expression [20]. Only one study, by Hieken et al, investigated the relationship between VEGF expression and local recurrence of DCIS, and the investigators found that VEGF was not an independent predictor of recurrence. In that study, DCIS that recurred was more likely than DCIS that did not recur to express VEGF, but this difference did not reach statistical significance (Table 9) [48].

\section{Heparanase-I}

Heparanase-1 (HPR-1), an endo- $\beta$-Dglucuronidase, is responsible for cleaving the glycosidic side chains of heparin sulfate proteoglycans. HPR-1 has not been extensively investigated in DCIS, even though an association has been found between HPR-1 and invasive cancer [56]. Maxhimer et al reported that the expression rate of HPR-1 in DCIS was $33.3 \%$. The expression rate of HPR-1 was significantly higher in comedo DCIS than in noncomedo DCIS ( $75 \%$ vs. $14 \%$ ). The investigators found that tissues from normal breast did not express HPR-1 and that the rate of expression of HPR-1 in DCIS with microinvasion was $83 \%$ [56]. In our comprehensive review, we did not identify any studies on the relationship between expression of HPR-1 and recurrence of DCIS.

\section{Epidermal Growth Factor Receptor Family}

HER2

Besides the steroid receptors, ER and PR, HER2 is one of the most extensively studied biological markers in DCIS. Studies have found HER2 to be of prognostic significance in invasive cancer; however, its importance in DCIS has yet to be elucidated [57]. Among the 36 studies in our review that examined HER2 expression rate in DCIS, the mean expression rate was $40.1 \%$ (range: 9-67\%, Table 6). HER2 testing in majority of the studies was different. Some studies assessed HER2 expression based on membrane staining, whereas, other more recent studies assessed HER2 expression from the results of FISH amplification. This complete information is included in Table 6. Expression rates of human epidermal growth factor receptor (HER) family in DCIS in "definition of positivity." Most of the studies in our review that investigated HER2 expression rates by subtype found that HER2 expression to be more common in the comedo subtype than in other subtypes of DCIS $[7,9,17]$.

Several studies investigated the relationship between HER2 and other biological markers. A few studies showed HER2 to be inversely correlated with ER and PR expression [9, 12, 17, 57]. One study showed HER2 to be positively associated with p53 expression [16]. A few studies showed HER2 overex- 
pression to be negatively associated with Bcl-2 expression $[16,22]$. The majority of the studies in our comprehensive review showed HER2 overexpression to be positively and significantly correlated with high nuclear grade $[9,10,12,17,18,22,36,57,58]$. However, one study did not show a significant association between HER2 overexpression and grade [20]. One study showed HER2 overexpression to be significantly correlated with proliferative activity [12]. In the same study, HER2 overexpression was significantly associated with p21 status [12].

We identified 15 (2,365 total patients) studies that evaluated the relationship between HER2 expression and local recurrence in DCIS. Eleven of these studies revealed no significant correlation between HER2 and disease recurrence. As mentioned previously, Ringberg et al evaluated a cell biological index that included ER and PR negativity, overexpression of HER2, low Bcl-2 expression, accumulation of p53, nondiploidy, and high Ki-67 expression; this study showed that the index was significantly associated with disease recurrence [16]. Provenzano et al, in a nested case-control study, found HER2 positivity to be individually associated with disease recurrence. In that study, DCIS that subsequently recurred was more likely than DCIS that did not recur to be HER2 positive $(41 \%$ vs. $12 \%$, Table 9). Kepple et al reported that HER2 positivity was an independent predictor of local-regional recurrence and that HER2 positivity in association with ER positivity was also a predictor of local-regional recurrence. However, it is difficult to interpret the effect of HER2 expression on local recurrence in this study because there were only 37 patients who underwent breast-conserving therapy (with or without radiotherapy), and only four patients had a recurrence [59]. Kerlikowske et al by multivariate analysis did not find HER2 to be an independent predictor of disease recurrence, but they did find in the univariate analysis that HER2 individually and the phenotype HER2+ER-Ki-67+ phenotype were associated with DCIS recurrence. DCIS that recurred was more likely to exhibit the ER-HER2+ phenotype than was DCIS that did not recur ( $19 \%$ vs. $6.4 \%$, respectively, Table 9). In the multivariate analysis, the HER2+ ER-Ki-67+ phenotype was a strong predictor of subsequent DCIS recurrence (OR: 5.8; 95\% CI: 2.4-14, Table 9). [24]. Zhou et al evaluated HER2 together with ER and PR and found that basal-like DCIS (negative for ER, PR, and HER2) was more likely to recur than was non-basal-like DCIS (HR: 1.7 vs. 1.8, Table 9). However, this difference did not reach statistical significance [25]. Holmes et al reported HER2 overexpression to be an independent predictor of recurrence. All the patients $(n=141)$ in this study were treated with lumpectomy alone, and 60 (42.6\%) recurrences were reported at a median follow-up of 10.2 years. In the univariate analysis, HER2 overexpression was significantly related to time to recurrence (Table 9). In the multivariate analysis, HER2 positivity $(3+)$ was a strong predictor of recurrence (HR: 1.82, 95\% CI: $1.03-3.22, P=0.041$, Table 9). The overall recurrence rate in this study, $42.6 \%$, is considered to be high and may reflect the fact that the study covered a long time period, with some patients treated as early as 1983 [58].

\section{HERI, HER3, and HER4}

Few studies have been conducted to investigate the rates of expression of HER1, HER3, and HER4 in DCIS and the relationship between expression of these markers and risk of local recurrence. The mean HER1 expression rate in DCIS in the three studies included in our review was $23.8 \%$ (rates in the individual studies were $13 \%, 22 \%$, and $36.4 \%$, Table 6 ). The mean HER3 expression rate in DCIS in the two studies included in our review was 59\% (rates in the individual studies were $56 \%$ and $62 \%$, Table 6 ). Finally, the mean HER4 expression rate in DCIS in the two studies that we reviewed was $46 \%$ (rates in the individual studies were $37 \%$ and $55 \%$, Table 6 ). No significant correlations were observed between expression of these three biological markers and high-grade vs. low-grade DCIS [15]. Studies also investigated the relationship of HER1, HER2, and HER3 to other markers. One study showed no correlation between these three biological markers and Ki-67 [15]. In the same study, overexpression of c-myc was significantly associated with HER3 and HER4 overexpression; however, no correlation as observed between c-myc overexpression and HER1.

In our comprehensive search, we identified two studies that investigated the recurrence risk associated with the expression of HER1, HER3, and HER4. Altintas et al found that none of these three markers was associated with disease recurrence either individually or in combination with other markers [15]. Barnes et al reported similar findings for HER1 and HER3; however, they observed that HER4 negativity was an independent predictor of recurrence. DCIS that did not recur was more likely than DCIS that did recur to overexpress HER4 (63.3\% vs. $35.9 \%$, respectively, Table 9). Both of these studies also investigated patterns of co-expression of HER1-4 with other markers. Barnes et al found that DCIS lesions with the combination of HER2 and HER4 expression were more likely to express ER than were tumors with HER2 expression without HER4 expression (73.2\% vs. $52.5 \%)$ [35]. Altintas et al found that DCIS lesions 
negative for both HER2 and HER4 were more likely to be high-grade lesions in cases (with a recurrence) than in controls (without a recurrence) $(90 \%$ vs. $57.4 \%)$. In the multivariate analysis, expressions of HER1-4 were not independent predictors of local recurrence. In this study, size, margin status, grade/necrosis, and age were the only independent risk factors for local recurrence [15].

\section{Extracellular matrix-related proteins CDIO}

CD10 is a zinc-dependent membrane metalloproteinase. This surface biomarker is also known as common acute lymphoblastic leukemia antigen [60]. The mean expression rate of CD10 in DCIS in the two studies included in our review was $22.9 \%$ (rates in the individual studies were $18.8 \%$ and $27 \%$, Table 7 ). CD10 expression was found primarily in the myoepithelial cells $[60,61]$. In a cohort study, Toussaint et al evaluated normal breast tissue and samples of DCIS and observed expression of CD10 to be lower in DCIS samples than in normal breast tissue [60]. In another cohort study, Witkiewicz et al found a significant association between the expression of CD10 and younger patient age. This was the only study to investigate the relationship between CD10 and other biological markers, and the investigators only found CD10 to be correlated with the glycoprotein secreted protein acidic and rich in cysteine (SPARC) [61]. In our comprehensive search, we identified two studies that investigated the relationship between CD10 expression and risk of recurrence in DCIS. Toussaint et al found low (as opposed to high) CD10 mRNA level in DCIS samples to be significantly associated with risk of recurrence (HR: 2.39; 95\% CI: 1.52-3.76, $P=0.001$, Table 9). Of the 154 patients in this study, 20 had had a recurrence $(13 \%)$ at a median follow-up time of 6 years [60]. Interestingly, the opposite relationship between CD10 and recurrence risk was found by Witkiewicz et al. In their study, strong stromal CD10 expression was significantly associated with disease recurrence (OR: 10.2, 95\% CI: 2.7, 37.7, Table 9). This study included 97 patients, and 21 (recurrence rate of $21.6 \%$ ) had had a recurrence at a median follow-up time of 9.2 years [61].

\section{Secreted Protein Acidic and Rich in Cysteine}

SPARC, a 32-kDa glycoprotein, plays an important role in cell matrix interactions and cell cycle progression [61]. We identified only one study that investigated the rate of SPARC expression in DCIS and the relationship between SPARC expression and recurrence in DCIS. Witkiewicz et al reported a SPARC expression rate of $24.7 \%$ (Table 7). These in- vestigators found SPARC to be an independent predictor of recurrence: patients with recurrence were more likely than patients without recurrence to have strong stromal SPARC expression (OR: 3.9, 95\% CI: 1.1, 14.3) [61].

\section{Cyclooxygenase-2}

COX-2 overexpression has been shown to be upregulated in neoplastic and preneoplastic lesions in the breast [21]. COX-2 is well known to be the rate-limiting enzyme in prostaglandin synthesis. Among the 10 studies in our review that examined COX-2 expression rate in DCIS, the mean COX-2 expression rate was $62.4 \%$ (range: $44.4-87.8 \%$, Table 8 ). Gauthier et al found COX-2 expression to be associated with phospho-p38 staining. P38, a stress-activated kinase, is one of the few markers that has not been investigated in much depth in DCIS [62]. In this cohort of 30 DCIS cases that were available for immunostaining, $61 \%$ of the cases overexpressed COX-2; $83 \%$ and $87 \%$ of the cases, respectively, expressed nuclear and cytoplasmic phospho-p38. All cases in which there was strong COX-2 staining exhibited moderate to high nuclear staining of phospho-p38. However, in cases with high nuclear staining of phospho-p38, the intensity of COX-2 staining varied from low to high [62]. In a few studies, COX-2 was observed to be significantly correlated with high nuclear grade $[19,63,64]$. One study showed COX-2 expression to be correlated with cytoplasmic survivin expression in DCIS [54]. Another study found COX-2 expression to be significantly associated with high Ki-67 expression, ER negativity, and HER2 positivity [19]. However, another study did not find COX-2 overexpression to be significantly associated with HER2 overexpression [21].

We identified four studies that investigated the relationship between COX-2 expression and risk of local-regional recurrence in DCIS. Barnes et al found greater COX-2 expression in DCIS that recurred than in DCIS that did not recur. Multivariate analysis revealed COX-2 expression to be an independent predictor of recurrence in DCIS. In addition, co-expression of COX-2 and cytoplasmic survivin was found in $70 \%$ of the recurrent cases, whereas none of the cases lacking expression of both of those biomarkers recurred within 5 years [54]. Kulkarni et al found that COX-2 expression was an independent predictor of recurrence in both the univariate and multivariate analyses. In addition, DCIS that recurred was more likely than DCIS that did not recur to express COX-2 (67\% vs. 29\%, respectively, Table 9) [21]. Gauthier et al found that high COX-2 expression in combination with high p16 expression and high Ki-67 
expression was a risk factor for recurrence [45]. In a follow-up study, Kerlikowske et al did not find COX-2 to be an independent predictor or individually associated with recurrence; however, COX-2 in combination with other phenotypes was a strong predictor and associated with recurrence. In the univariate analysis, cases with subsequent invasive recurrence were more likely to express COX-2, p16, and Ki-67 than were cases that did not recur $(23 \%$ vs. $8.5 \%$, respectively, Table 9) [24]. Cases with DCIS recurrence were more likely than cases without recurrence to have the phenotype COX-2-Ki- $67+$ p $16+(19 \%$ vs. $2.6 \%$, Table 9). In the multivariate analysis, the p16, COX-2, and Ki-67 triple-positive phenotype was a strong predictor of subsequent invasive recurrence (HR: 2.2; 95\% CI: 1.1-4.5; Table 9); whereas the p16+COX-2-Ki-67+ phenotype was a strong predictor of subsequent DCIS recurrence (HR: 3.7; 95\% CI: 1.7-7.9; Table 9). [24]. The study by Bundred et al discussed earlier in this article revealed that use of celecoxib, a COX-2 inhibitor, for 2 weeks prior to surgery had no demonstrable effect on proliferation or apoptosis in DCIS [30]. These authors concluded that the use of COX-2 inhibitors would be unlikely to have a therapeutic value in DCIS [30].

\section{Summary}

It was difficult to elucidate the prognostic importance of the biomarkers investigated in this comprehensive review because of heterogeneous treatment approaches and often conflicting results. Although the studies in this review provide valuable information on the diagnostic and prognostic significance of the studied markers, another factor that limits our ability to draw conclusions on the basis of the information in this review is the fact that many of the studies reviewed included only small numbers of patients. Other studies included groups of patients treated with different therapies, and in some studies the treatment was inconsistent. In addition, several studies included patients who had received endocrine therapy or radiotherapy, while other studies did not. This heterogeneous treatment makes it hard to assess clinical outcome. In conclusion, novel and key breast cancer biological markers need to be studied prospectively in large cohorts of patient to differentiate indolent from aggressive DCIS and tailor the need and extent of therapies.

\section{Conflict of Interest}

The authors have declared that no conflict of interest exists.

\section{References}

1. Kuerer HM. Rational individualised selection of adjuvant therapy for ductal carcinoma in situ. Lancet Oncol 2010;12:2-3

2. Allegra CJ, Aberle DR, Ganschow $P$, et al. National Institutes of Health State-of-the-Science Conference statement: Diagnosis and Management of Ductal Carcinoma In Situ September 22-24, 2009. J Natl Cancer Inst 2010;102:161-9

3. Madu CO and $\mathrm{Lu} \mathrm{Y}$. Novel diagnostic biomarkers for prostate cancer. J Cancer 2010;1:150-77

4. Barker PE. Cancer biomarker validation: standards and process: roles for the National Institute of Standards and Technology (NIST). Ann N Y Acad Sci 2003;983:142-50

5. Ludwig JA and Weinstein JN. Biomarkers in cancer staging, prognosis and treatment selection. Nat Rev Cancer 2005;5:845-56

6. McShane LM, Altman DG, Sauerbrei W, et al. Reporting recommendations for tumor marker prognostic studies (REMARK). J Natl Cancer Inst 2005;97:1180-4

7. Albonico G, Querzoli P, Ferretti S, et al. Biological profile of in situ breast cancer investigated by immunohistochemical technique. Cancer Detect Prev 1998;22:313-8

8. Hanley K, Wang J, Bourne $\mathrm{P}$, et al. Lack of expression of androgen receptor may play a critical role in transformation from in situ to invasive basal subtype of high-grade ductal carcinoma of the breast. Hum Pathol 2008;39:386-92

9. Claus EB, Chu P, Howe CL, et al. Pathobiologic findings in DCIS of the breast: morphologic features, angiogenesis, HER-2/neu and hormone receptors. Exp Mol Pathol 2001;70:303-16

10. Bijker N, Peterse JL, Duchateau L, et al. Histological type and marker expression of the primary tumour compared with its local recurrence after breast-conserving therapy for ductal carcinoma in situ. Br J Cancer 2001;84:539-44

11. Lebrecht A, Buchmann J, Hefler L, et al. Histological category and expression of hormone receptors in ductal carcinoma in situ of the breast. Anticancer Res 2002;22:1909-11

12. Lebeau A, Unholzer A, Amann G, et al. EGFR, HER-2/neu, cyclin D1, p21 and p53 in correlation to cell proliferation and steroid hormone receptor status in ductal carcinoma in situ of the breast. Breast Cancer Res Treat 2003;79:187-98

13. Collins LC and Schnitt SJ. HER2 protein overexpression in estrogen receptor-positive ductal carcinoma in situ of the breast: frequency and implications for tamoxifen therapy. Mod Pathol 2005;18:615-20

14. Meijnen $\mathrm{P}$, Peterse JL, Antonini N, et al. Immunohistochemical categorisation of ductal carcinoma in situ of the breast. Br J Cancer 2008;98:137-42

15. Altintas S, Lambein K, Huizing MT, et al. Prognostic significance of oncogenic markers in ductal carcinoma in situ of the breast: a clinicopathologic study. Breast J 2009;15:120-32

16. Ringberg A, Anagnostaki L, Anderson $\mathrm{H}$, et al. Cell biological factors in ductal carcinoma in situ (DCIS) of the breast-relationship to ipsilateral local recurrence and histopathological characteristics. Eur J Cancer 2001;37:1514-22

17. DiGiovanna MP, Chu P, Davison TL, et al. Active signaling by HER-2/neu in a subpopulation of HER-2/neu-overexpressing ductal carcinoma in situ: clinicopathological correlates. Cancer Res 2002;62:6667-73

18. Kuerer HM, Buzdar AU, Mittendorf EA, et al. Biologic and immunologic effects of preoperative trastuzumab for ductal carcinoma in situ of the breast. Cancer 2011;117(1):39-47

19. Boland GP, Butt IS, Prasad R, et al. COX-2 expression is associated with an aggressive phenotype in ductal carcinoma in situ. Br J Cancer 2004;90:423-9

20. Perrone G, Santini D, Vincenzi B, et al. COX-2 expression in DCIS: correlation with VEGF, HER-2/neu, prognostic molecu- 
lar markers and clinicopathological features. Histopathology 2005;46:561-8

21. Kulkarni S, Patil DB, Diaz LK, et al. COX-2 and PPARgamma expression are potential markers of recurrence risk in mammary duct carcinoma in-situ. BMC Cancer 2008;8:36

22. Provenzano E, Hopper JL, Giles GG, et al. Biological markers that predict clinical recurrence in ductal carcinoma in situ of the breast. Eur J Cancer 2003;39:622-30

23. Roka S, Rudas M, Taucher S, et al. High nuclear grade and negative estrogen receptor are significant risk factors for recurrence in DCIS. Eur J Surg Oncol 2004;30:243-7

24. Kerlikowske K, Molinaro AM, Gauthier ML, et al. Biomarker expression and risk of subsequent tumors after initial ductal carcinoma in situ diagnosis. J Natl Cancer Inst 2010;102:627-37

25. Zhou W, Jirstrom K, Johansson C, et al. Long-term survival of women with basal-like ductal carcinoma in situ of the breast: a population-based cohort study. BMC Cancer 2010;10:653

26. Ma CX, Sanchez CG and Ellis MJ. Predicting endocrine therapy responsiveness in breast cancer. Oncology (Williston Park) 2009;23:133-42

27. Cuzick J, Sestak I, Pinder SE, et al. Effect of tamoxifen and radiotherapy in women with locally excised ductal carcinoma in situ: long-term results from the UK/ANZ DCIS trial. Lancet Oncol 2011;12:21-9

28. Eng-Wong J, Costantino JP and Swain SM. The impact of systemic therapy following ductal carcinoma in situ. J Natl Cancer Inst Monogr 2010;2010:200-3

29. Chen YY, DeVries S, Anderson J, et al. Pathologic and biologic response to preoperative endocrine therapy in patients with ER-positive ductal carcinoma in situ. BMC Cancer 2009;9:285

30. Bundred NJ, Cramer A, Morris J, et al. Cyclooxygenase-2 inhibition does not improve the reduction in ductal carcinoma in situ proliferation with aromatase inhibitor therapy: results of the ERISAC randomized placebo-controlled trial. Clin Cancer Res 2010;16:1605-12

31. Millar EK, Tran K, Marr P, et al. p27KIP-1, cyclin A and cyclin D1 protein expression in ductal carcinoma in situ of the breast: p27KIP-1 correlates with hormone receptor status but not with local recurrence. Pathol Int 2007;57:183-9

32. Birrell SN, Hall RE and Tilley WD. Role of the androgen receptor in human breast cancer. J Mammary Gland Biol Neoplasia 1998;3:95-103

33. Yu Q, Niu Y, Liu N, et al. Expression of androgen receptor in breast cancer and its significance as a prognostic factor. Ann Oncol 2010; Epub

34. de Azambuja E, Cardoso F, de Castro GJr., et al. Ki-67 as prognostic marker in early breast cancer: a meta-analysis of published studies involving 12,155 patients. $\mathrm{Br} \mathrm{J}$ Cancer 2007;96:1504-13

35. Barnes NL, Khavari S, Boland GP, et al. Absence of HER4 expression predicts recurrence of ductal carcinoma in situ of the breast. Clin Cancer Res 2005;11:2163-8

36. Warnberg F, Nordgren $\mathrm{H}$, Bergkvist L, et al. Tumour markers in breast carcinoma correlate with grade rather than with invasiveness. Br J Cancer 2001;85:869-74

37. Wilson GR, Cramer A, Welman A, et al. Activated c-SRC in ductal carcinoma in situ correlates with high tumour grade, high proliferation and HER2 positivity. $\mathrm{Br} \mathrm{J}$ Cancer 2006;95:1410-4

38. Chasle J, Delozier T, Denoux Y, et al. Immunohistochemical study of cell cycle regulatory proteins in intraductal breast carcinomas--a preliminary study. Eur J Cancer 2003;39:1363-9

39. Zhou CJ, Zhang QH, Zhang TG, et al. Expression of ER, Ki-67 and cylinD1 in the pre-cancerous breast of Chinese patients. Pathol Oncol Res 2009;15:153-8
40. Guo LL, Gao P, Wu YG, et al. Alteration of cyclin D1 in Chinese patients with breast carcinoma and its correlation with Ki-67, pRb, and p53. Arch Med Res 2007;38:846-52

41. Oh YL, Choi JS, Song SY, et al. Expression of p21Waf1, p27Kip1 and cyclin D1 proteins in breast ductal carcinoma in situ: Relation with clinicopathologic characteristics and with p53 expression and estrogen receptor status. Pathol Int 2001;51:94-9

42. Jirstrom K, Ringberg A, Ferno $M$, et al. Tissue microarray analyses of G1/S-regulatory proteins in ductal carcinoma in situ of the breast indicate that low cyclin D1 is associated with local recurrence. Br J Cancer 2003;89:1920-6

43. de Roos MA, de Bock GH, de Vries J, et al. p53 overexpression is a predictor of local recurrence after treatment for both in situ and invasive ductal carcinoma of the breast. J Surg Res 2007;140:109-14

44. Steeg PS and Zhou Q. Cyclins and breast cancer. Breast Cancer Res Treat 1998:52:17-28

45. Gauthier ML, Berman HK, Miller C, et al. Abrogated response to cellular stress identifies DCIS associated with subsequent tumor events and defines basal-like breast tumors. Cancer Cell 2007;12:479-91

46. Cornfield DB, Palazzo JP, Schwartz GF, et al. The prognostic significance of multiple morphologic features and biologic markers in ductal carcinoma in situ of the breast: a study of a large cohort of patients treated with surgery alone. Cancer 2004;100:2317-27

47. Alkarain A, Jordan R and Slingerland J. p27 deregulation in breast cancer: prognostic significance and implications for therapy. J Mammary Gland Biol Neoplasia 2004;9:67-80

48. Hieken TJ, Farolan M, D'Alessandro S, et al. Predicting the biologic behavior of ductal carcinoma in situ: an analysis of molecular markers. Surgery 2001;130:593-600

49. Rehman S, Crow J and Revell PA. Bax protein expression in DCIS of the breast in relation to invasive ductal carcinoma and other molecular markers. Pathol Oncol Res 2000;6:256-63

50. Dawson SJ, Makretsov N, Blows FM, et al. BCL2 in breast cancer: a favourable prognostic marker across molecular subtypes and independent of adjuvant therapy received. Br J Cancer 2010;103:668-75

51. Chen MK, Yang SF, Lai JC, et al. Expression of bcl-2 correlates with poor prognosis and modulates migration of nasopharyngeal carcinoma cells. Clin Chim Acta 2010;411:400-5

52. Okumura Y, Yamamoto $Y$, Zhang Z, et al. Identification of biomarkers in ductal carcinoma in situ of the breast with microinvasion. BMC Cancer 2008:8:287

53. Anagnostopoulos GK, Stefanou D, Arkoumani E, et al. Expression of Bax protein in gastric carcinomas. A clinicopathological and immunohistochemical study. Acta Gastroenterol Belg 2007;70:285-9

54. Barnes N, Haywood P, Flint P, et al. Survivin expression in in situ and invasive breast cancer relates to COX-2 expression and DCIS recurrence. Br J Cancer 2006;94:253-8

55. Perez EA, Jenkins RB, Dueck AC, et al. C-MYC Alterations and Association With Patient Outcome in Early-Stage HER2-Positive Breast Cancer From the North Central Cancer Treatment Group N9831 Adjuvant Trastuzumab Trial. J Clin Oncol 2011; 29(6):651-9

56. Maxhimer JB, Pesce CE, Stewart RA, et al. Ductal carcinoma in situ of the breast and heparanase-1 expression: a molecular explanation for more aggressive subtypes. J Am Coll Surg 2005;200:328-35

57. Latta EK, Tjan S, Parkes RK, et al. The role of HER2/neu overexpression/amplification in the progression of ductal carcinoma in situ to invasive carcinoma of the breast. Mod Pathol 2002;15:1318-25 
58. Holmes P, Lloyd J, Chervoneva I, et al. Prognostic markers and long-term outcomes in ductal carcinoma in situ of the breast treated with excision alone. Cancer 2011; Epub

59. Kepple J, Henry-Tillman RS, Klimberg VS, et al. The receptor expression pattern in ductal carcinoma in situ predicts recurrence. Am J Surg 2006;192:68-71

60. Toussaint J, Durbecq V, Altintas S, et al. Low CD10 mRNA expression identifies high-risk ductal carcinoma in situ (DCIS). PLoS One 2010;5: e12100

61. Witkiewicz AK, Freydin B, Chervoneva I, et al. Stromal CD10 and SPARC expression in ductal carcinoma in situ (DCIS) patients predicts disease recurrence. Cancer Biol Ther 2010;10:391-6

62. Gauthier ML, Pickering CR, Miller CJ, et al. p38 regulates cyclooxygenase- 2 in human mammary epithelial cells and is activated in premalignant tissue. Cancer Res 2005;65:1792-9

63. Tan KB, Yong WP and Putti TC. Cyclooxygenase-2 expression: a potential prognostic and predictive marker for high-grade ductal carcinoma in situ of the breast. Histopathology 2004;44:24-8

64. de la Torre J, Sabadell MD, Rojo F, et al. Cyclo-oxygenase type 2 is dysregulated in breast ductal carcinoma in situ and correlates with poor outcome. Eur J Obstet Gynecol Reprod Biol 2010;151:72-6

65. Bryan BB, Schnitt SJ and Collins LC. Ductal carcinoma in situ with basal-like phenotype: a possible precursor to invasive basal-like breast cancer. Mod Pathol 2006;19:617-21

66. Livasy CA, Perou CM, Karaca G, et al. Identification of a basal-like subtype of breast ductal carcinoma in situ. Hum Pathol 2007:38:197-204
67. Tamimi RM, Baer HJ, Marotti J, et al. Comparison of molecular phenotypes of ductal carcinoma in situ and invasive breast cancer. Breast Cancer Res 2008;10:R67

68. Roses RE, Paulson EC, Sharma A, et al. HER-2/neu overexpression as a predictor for the transition from in situ to invasive breast cancer. Cancer Epidemiol Biomarkers Prev 2009;18:1386-9

69. Suzuki J, Chen YY, Scott GK, et al. Protein acetylation and histone deacetylase expression associated with malignant breast cancer progression. Clin Cancer Res 2009;15:3163-71

70. Yu KD, Wu LM, Liu GY, et al. Different Distribution of Breast Cancer Subtypes in Breast Ductal Carcinoma in situ (DCIS), DCIS with Microinvasion, and DCIS with Invasion Component. Ann Surg Oncol 2010; 18(5):1342-8

71. Behling KC, Tang A, Freydin B, et al. Increased SIAH expression predicts ductal carcinoma in situ (DCIS) progression to invasive carcinoma. Breast Cancer Res Treat 2010; Epub

72. Menter DG, Hoque A, Motiwala N, et al. Computerized image analysis of Ki-67 in ductal breast carcinoma in situ. Anal Quant Cytol Histol 2001;23:218-28

73. Hoque A, Sneige N, Sahin AA, et al. Her-2/neu gene amplification in ductal carcinoma in situ of the breast. Cancer Epidemiol Biomarkers Prev 2002;11:587-90

74. Stackievicz R, Paran H, Bernheim J, et al. Prognostic significance of HER-2/neu expression in patients with ductal carcinoma in situ. Isr Med Assoc J 2010;12:290-5

\section{Tables}

Table I. Classification scheme of biological markers evaluated in the comprehensive review

\begin{tabular}{|c|c|}
\hline Steroid receptors & Estrogen receptor, progesterone receptor, and androgen receptor \\
\hline Proliferation marker & Ki-67 \\
\hline $\begin{array}{l}\text { Cell cycle regulation and apoptotic } \\
\text { markers }\end{array}$ & cyclin D1, cyclin A, cyclin E, p16, p21, p27, p53, Bcl-2, Bax, Survivin, c-myc, and retinoblastoma \\
\hline Angiogenesis related proteins & Vascular endothelial growth factor and heparanase-1 \\
\hline Epidermal growth factor receptor family & HER1, HER2, HER3, and HER4 \\
\hline \multirow[t]{2}{*}{ Extracellular matrix related proteins } & CD10 \\
\hline & Secreted protein acidic and rich in cysteine \\
\hline Other biological marker & COX-2 \\
\hline
\end{tabular}

Table 2. Expression rates of steroid receptors in DCIS

\begin{tabular}{clllll}
\hline Biomarker & $\begin{array}{l}\text { First author and } \\
\text { reference }\end{array}$ & Year & $\begin{array}{l}\text { No. of sam- } \\
\text { ples }\end{array}$ & $\begin{array}{l}\text { Expression } \\
\text { rate, } \%\end{array}$ & Definition of positivity \\
\hline Estrogen receptor (ER) & & & $28.8-92.6$ & $\begin{array}{l}\text { Nuclear staining in at least 10\% of tumor cells. } \\
28.8 \text { (comedo DCIS) }\end{array}$ \\
Albonico [7] & 1998 & 62 & & $\begin{array}{l}78.9 \text { (noncomedo DCIS) } \\
\text { 92.6 (cribriform DCIS) }\end{array}$ \\
& & & No cut-off value was mentioned in the paper. \\
Claus [9] & 2001 & 219 & 60 & Any ER expression. \\
Bijker [10] & 2001 & 116 & 62.9 & Nuclear staining in more than 10\% of tumor cells. \\
Ringberg [16] & 2001 & 187 & 60 & Nuclear staining in at least 10\% of tumor cells. \\
Wärnberg [36] & 2001 & 194 & 68 & Nuclear staining in more than 5\% of tumor cells. \\
Oh [41] & 2001 & 49 & 65.3 & Moderate or strong nuclear staining in tumor cells. \\
Lebrecht [11] & 2002 & 120 & 71.7 & &
\end{tabular}




$\begin{array}{lll}\text { DiGiovanna [17] } & 2002 & 219 \\ \text { Provenzano [22] } & 2003 & 95 \\ \text { Lebeau [12] } & 2003 & 45 \\ \text { Roka [23] } & 2004 & 190 \\ \text { Boland [19] } & 2004 & 187 \\ \text { Barnes [35] } & 2005 & 129 \\ \text { Perrone [20] } & 2005 & 49 \\ \text { Collins [13] } & 2005 & 148 \\ \text { Gauthier [62] } & 2005 & 30 \\ \text { Bryan [65] } & 2006 & 66 \\ \text { Kepple [59] } & 2006 & 94 \\ \text { Wilson [37] } & 2006 & 129 \\ \text { Barnes [54] } & 2006 & 161 \\ \text { Millar [31] } & 2007 & 60 \\ \text { Livasy [66] } & 2007 & 245 \\ \text { Meijnen [14] } & 2008 & 163 \\ \text { Hanley [8] } & 2008 & 90\end{array}$

Tamimi [67] 2008

Okumura [52] 2008

Kulkarni [21] 2008

Roses [68] 2009

Suzuki [69] 2009

Altintas [15] 2009

Yu K [70] 2010

$\begin{array}{llll}\text { Kuerer [18] } & 2010 & 69 & 81 \\ \text { Kerlikowske [24] } & 2010 & 329 & 77.9 \\ \text { Behling [71] } & 2010 & 65 & 78 \\ \text { Witkiewicz [61] } & 2010 & 97 & 96.6 \\ \text { Holmes [58] } & 2011 & 141 & 80.9\end{array}$

\section{Progesterone receptor (PR)}

Albonico

1998

62

$\begin{array}{lll}\text { Claus [9] } & 2001 & 219 \\ \text { Bijker [10] } & 2001 & 116 \\ \text { Ringberg [16] } & 2001 & 187 \\ \text { Wärnberg [36] } & 2001 & 194 \\ \text { DiGiovanna [17] } & 2002 & 219 \\ \text { Provenzano [22] } & 2003 & 95 \\ \text { Lebeau [12] } & 2003 & 45 \\ \text { Roka [23] } & 2004 & 190 \\ \text { Perrone [20] } & 2005 & 49 \\ \text { Gauthier [62] } & 2005 & 30 \\ \text { Bryan [65] } & 2006 & 66 \\ \text { Kepple [59] } & 2006 & 94\end{array}$

60

49

55

57.9

59.7

66.4

75.5

77

78.9

56

74

65.1

63.6

58.3

70

68

30 (high-grade DCIS);

96

(non-high-gr ade DCIS)

74

73.1

77.8

76.2

60

72

67.3

81

96.6

28.2-89.1

62

47.1

43

43

62

48

50

41

65.3

70.8

40

56
Nuclear staining in more than $10 \%$ of tumor cells.

Nuclear staining in at least $10 \%$ of tumor cells.

Nuclear staining in at least $10 \%$ of tumor cells.

Nuclear staining in at least $10 \%$ of tumor cells.

Nuclear staining in at least $5 \%$ of tumor cells.

Nuclear staining in at least $5 \%$ of tumor cells.

Nuclear staining in more than $10 \%$ of tumor cells.

Nuclear staining in at least $10 \%$ of tumor cells.

No cut-off value was mentioned in the paper.

Nuclear staining in at least $10 \%$ of tumor cells. All cases were high-nuclear-grade DCIS.

No cut-off value was mentioned in the paper

Nuclear staining in at least $5 \%$ of tumor cells.

Nuclear staining in at least $5 \%$ of tumor cells.

Nuclear staining in more than $10 \%$ of tumor cells.

Allred score above 2.

Any ER expression.

Nuclear staining in at least $10 \%$ of tumor cells.

Nuclear staining in more than $10 \%$ of tumor cells.

Nuclear staining in more than $10 \%$ of tumor cells.

Nuclear staining in at least $10 \%$ of tumor cells.

Allred score less than or equal to 3 .

Nuclear staining in at least $1 \%$ of tumor cells.

Nuclear staining in at least $10 \%$ of tumor cells.

Results of immunohistochemical assays were evaluated using a proportion score and an intensity score. Tumors that scored over 1 were scored as positive.

No cut-off value was mentioned in the paper.

Nuclear staining in at least $10 \%$ of tumor cells.

No cut-off value was mentioned in the paper.

Status obtained from the pathology reports.

Nuclear staining was assessed in tumors and assigned a score. Tumors with staining in $0-9 \%$ of cells were given a score of 3 , tumors with staining in $10-79 \%$ of cells were given a score of 2 , and tumors with staining in $80 \%$ or more of cells were given a score of 1 . Scores 1 and 2 were considered to be positive.

Nuclear staining in at least $10 \%$ of tumor cells.

28.2 (comedo DCIS)

75.3 (noncomedo DCIS)

89.1 (cribriform DCIS)

No cut-off value was mentioned in the paper.

Any PR expression.

Nuclear staining in more than $10 \%$ of tumor cells.

Nuclear staining in at least $10 \%$ of tumor cells.

Nuclear staining in more than $10 \%$ of tumor cells.

Nuclear staining in at least $10 \%$ of tumor cells.

Nuclear staining in at least $10 \%$ of tumor cells.

Nuclear staining in at least $10 \%$ of tumor cells.

Nuclear staining in more than $10 \%$ of tumor cells.

No cut-off value was mentioned in the paper.

Nuclear staining in at least $10 \%$ of tumor cells. All cases were high-nuclear-grade DCIS.

No cut-off value was mentioned in the paper. 


\begin{tabular}{|c|c|c|c|c|}
\hline Millar [31] & 2007 & 60 & 56.1 & Nuclear staining in more than $10 \%$ of tumor cells. \\
\hline Meijnen [14] & 2008 & 163 & 46 & Any PR expression. \\
\hline Hanley [8] & 2008 & 90 & $\begin{array}{l}23 \\
\text { (high-grade } \\
\text { DCIS); } \\
81 \\
\text { (non-high-gr } \\
\text { ade DCIS) }\end{array}$ & Nuclear staining in at least $10 \%$ of tumor cells. \\
\hline Tamimi [67] & 2008 & 272 & 59.9 & Nuclear staining in more than $10 \%$ of tumor cells. \\
\hline Okumura [52] & 2008 & 52 & 71.2 & Nuclear staining in more than $10 \%$ of tumor cells. \\
\hline Kulkarni [21] & 2008 & 69 & 75.9 & Nuclear staining in more than $10 \%$ of tumor cells. \\
\hline Roses [68] & 2009 & 84 & 68.3 & Allred score less than or equal to 3 . \\
\hline Suzuki [69] & 2009 & 58 & 55 & Nuclear staining in at least $1 \%$ of tumor cells. \\
\hline Altintas [15] & 2009 & 159 & 65 & Nuclear staining in at least $10 \%$ of tumor cells. \\
\hline Yu K [70] & 2010 & 271 & 52.7 & $\begin{array}{l}\text { Results of immunohistochemical assays were evaluated using a } \\
\text { proportion score and an intensity score. Tumors that scored over } 1 \\
\text { were scored as positive. }\end{array}$ \\
\hline Bundred [30] & 2010 & 90 & 72 & $\begin{array}{l}\text { Nuclear staining in more than } 5 \% \text { of tumor cells. All cases were } \\
\text { ER-positive DCIS. }\end{array}$ \\
\hline Kerlikowske [24] & 2010 & 329 & 74.5 & Nuclear staining in at least $10 \%$ of tumor cells. \\
\hline Behling [71] & 2010 & 65 & 71.2 & No cut-off value was mentioned in the paper. \\
\hline Witkiewicz [61] & 2010 & 97 & 83.3 & Status obtained from pathology reports. \\
\hline Holmes [58] & 2011 & 141 & 70.9 & $\begin{array}{l}\text { Nuclear staining was assessed in tumors and assigned a score. } \\
\text { Tumors with staining in } 0-9 \% \text { of cells were given a score of } 3 \text {, } \\
\text { tumors with staining in } 10-79 \% \text { of cells were given a score of } 2, \\
\text { and tumors with staining in } 80 \% \text { or more of cells were given a } \\
\text { score of } 1 \text {. Scores } 1 \text { and } 2 \text { were considered to be positive. }\end{array}$ \\
\hline \multicolumn{5}{|l|}{ Androgen receptor (AR) } \\
\hline Provenzano [22] & 2003 & 95 & 81 & Nuclear staining in at least $10 \%$ of tumor cells. \\
\hline Meijnen [14] & 2008 & 163 & 37 & Strong nuclear staining in more than $10 \%$ of tumor cells. \\
\hline Hanley $[8]$ & 2008 & 90 & $\begin{array}{l}89 \\
\text { (non-high-gr } \\
\text { ade DCIS); } \\
93 \\
\text { (high-grade } \\
\text { DCIS) }\end{array}$ & Nuclear staining in at least $10 \%$ of tumor cells. \\
\hline Yu Q. [33] & 2010 & 34 & 79.4 & Allred score of 2 . \\
\hline
\end{tabular}

Table 3. Expression rates of proliferation marker Ki-67 in DCIS

\begin{tabular}{|c|c|c|c|c|c|}
\hline Biomarker & $\begin{array}{l}\text { First author and } \\
\text { reference }\end{array}$ & Year & $\begin{array}{l}\text { No. of } \\
\text { samples }\end{array}$ & $\begin{array}{l}\text { Expression } \\
\text { rate, \% }\end{array}$ & Comments \\
\hline \multicolumn{6}{|l|}{ Ki-67 } \\
\hline & Albonico [7] & 1998 & 62 & $3.4-65.4$ & $\begin{array}{l}\text { Tumors with nuclear staining in more than } 13 \% \text { of cells } \\
\text { were scored as positive. } \\
65.4 \text { (comedo DCIS) } \\
7.5 \text { (noncomedo DCIS) } \\
3.4 \text { (cribriform DCIS) }\end{array}$ \\
\hline & Ringberg [16] & 2001 & 187 & 42 & $\begin{array}{l}42 \% \text { of cases exhibited staining in more than } 10 \% \text { of the } \\
\text { tumor cells. }\end{array}$ \\
\hline & Menter [72] & 2001 & 200 & $0.99-2.59$ & $\begin{array}{l}\text { Ki- } 67 \text { labeling index was determined by computerized } \\
\text { image analysis. The range of Ki- } 67 \text { labeling index in DCIS } \\
\text { nuclear grades I-III was } 0.99-2.59 \text {. }\end{array}$ \\
\hline & Wärnberg [36] & 2001 & 194 & 19 & $\begin{array}{l}19 \% \text { of cases exhibited staining in at least } 10 \% \text { of the tumor } \\
\text { cells. }\end{array}$ \\
\hline & Lebeau [12] & 2003 & 45 & 45.5 & $\begin{array}{l}45.5 \% \text { of cases exhibited staining in more than } 10 \% \text { of the } \\
\text { tumor cells. }\end{array}$ \\
\hline & Boland [19] & 2004 & 187 & 49.2 & $\begin{array}{l}\text { The percentage of positively stained nuclei (at least 1,000 } \\
\text { cells were counted for each case) was determined using a } \\
\text { grid graticule and cell counter at X400 magnification. } 50.8 \% \\
\text { of cases exhibited staining in at least } 10 \% \text { of tumor cells. }\end{array}$ \\
\hline & Barnes [35] & 2005 & 129 & $\begin{array}{l}10.9 \text { (nonre- } \\
\text { current }\end{array}$ & $\begin{array}{l}\text { The percentage of positively stained nuclei (at least } 1,000 \\
\text { cells were counted for each case) was determined using a }\end{array}$ \\
\hline
\end{tabular}


DCIS);

15.5 (recur-

rent DCIS)

Barnes [54]

2006

161

8.7-14.4

Wilson [37]

2006

129

Gauthier [45]

2007

Livasy [66]

Okumura [52]

2008

Altintas [15]

2009

Kuerer [18]

2010

Kerlikowske [24]

2010

329

47.5

Bundred [30]

201090 grid graticule and cell counter at X400 magnification. The median percentage of cells with Ki-67 expression was $10.9-15.5 \%$

The percentage of positively stained nuclei (at least 1,000 cells were counted for each case) was determined using a grid graticule and cell counter at X400 magnification. The median percentage of cells with Ki-67 expression was $8.7-14.4 \%$.

$50.4 \quad$ The percentage of positively stained nuclei (at least 1.000 cells were counted for each case) was determined using a grid graticule and cell counter at X400 magnification. 50.4\% of cases exhibited staining in at least $10 \%$ of tumor cells.

$37.1 \%$ of cases exhibited staining in more than $10 \%$ of the tumor cells.

$36 \%$ of cases exhibited staining in more than $10 \%$ of the tumor cells.

The percentage of cancer cells with positively stained nuclei was determined. The mean percentage Ki-67 staining was $17.9 \pm 1.5 \%$

$36 \%$ of cases exhibited staining in more than $10 \%$ of the tumor cells.

No cut-off value was mentioned in the paper. The mean $( \pm$ standard deviation) percentage of cells with Ki-67 staining was $44.29 \pm 3.42 \%$. Only patients with HER2-positive DCIS were included in the study.

$47.5 \%$ of cases exhibited staining in more than $10 \%$ of the tumor cells, and thus $47.5 \%$ was set as the median value (positive cells divided by the number of positive plus negative cells) to divide cases with low and high proliferative activity.

Ki-67 scores were calculated as the percentage of positively stained nuclei. The median percentages in each of the different treatment subgroups in this randomized trial were reported before patients were given aromatase inhibitor therapy. All patients had ER-positive DCIS.

Table 4. Expression rates of cell cycle regulation and apoptotic markers in DCIS

\begin{tabular}{|c|c|c|c|c|c|}
\hline Biomarker & $\begin{array}{l}\text { First author and } \\
\text { reference }\end{array}$ & Year & $\begin{array}{l}\text { No. of } \\
\text { samples }\end{array}$ & $\begin{array}{l}\text { Expression } \\
\text { rate, \% }\end{array}$ & Definition of positivity \\
\hline \multicolumn{6}{|l|}{ cyclin D1 } \\
\hline & Oh [41] & 2001 & 49 & 59.2 & $\begin{array}{l}\text { Moderate or strong nuclear staining in more than } 10 \% \text { of } \\
\text { tumor cells. }\end{array}$ \\
\hline & Lebeau [12] & 2003 & 45 & 48.8 & Nuclear staining in more than $10 \%$ of tumor cells. \\
\hline & Chasle [38] & 2003 & 50 & 37 & $\begin{array}{l}\text { The percentage of marked nuclei was determined for } \\
300-400 \text { nuclei in the most positive foci. The mean for cyclin } \\
\text { D1 was reported to be } 37 \% \text {. }\end{array}$ \\
\hline & Millar [31] & 2007 & 60 & 58 & Nuclear staining in more than $5 \%$ of tumor cells. \\
\hline & Okumura [52] & 2008 & 52 & 70.6 & Nuclear staining in more than $10 \%$ of tumor cells. \\
\hline & Kulkarni [21] & 2008 & 69 & 61.5 & Nuclear staining in at least $10 \%$ of tumor cells. \\
\hline \multicolumn{6}{|l|}{$\operatorname{cyclin} A$} \\
\hline & Millar [31] & 2007 & 60 & 35 & Nuclear staining in more than $10 \%$ of tumor cells. \\
\hline \multicolumn{6}{|l|}{ cyclin $E$} \\
\hline & Jirström [42] & 2003 & 92 & 25 & $\begin{array}{l}\text { A mean value was used as a cut-off to divide expression of } \\
\text { cyclin E. }\end{array}$ \\
\hline \multicolumn{6}{|l|}{$p 16$} \\
\hline & Jirström [42] & 2003 & 92 & 37.5 & $\begin{array}{l}\text { A mean value was used as a cut-off to divide expression of } \\
\text { p16. }\end{array}$ \\
\hline & Gauthier [45] & 2007 & 70 & 28 & Allred score of at least 2 . \\
\hline & Kerlikowske [24] & 2010 & 329 & 39.3 & On a 3-point scale, a score of at least 2. \\
\hline \multicolumn{6}{|l|}{$p 21$} \\
\hline & Oh [41] & 2001 & 49 & 67.3 & $\begin{array}{l}\text { Moderate or strong nuclear staining in more than } 10 \% \text { of } \\
\text { tumor cells. }\end{array}$ \\
\hline & Provenzano [22] & 2003 & 95 & 34 & On a 6-point scale, a score of 4-6 (moderate or strong stain- \\
\hline
\end{tabular}




\begin{tabular}{|c|c|c|c|c|c|}
\hline & & & & & ing). \\
\hline & Lebeau [12] & 2003 & 45 & 42.2 & Nuclear staining in more than $10 \%$ of tumor cells. \\
\hline & Chasle [38] & 2003 & 50 & 76 & $\begin{array}{l}\text { The percentage of marked nuclei was determined for } \\
300-400 \text { nuclei in the most positive foci. }\end{array}$ \\
\hline & Okumura [52] & 2008 & 52 & 69.2 & Nuclear staining in more than $10 \%$ of tumor cells. \\
\hline & Kulkarni [21] & 2008 & 69 & 29.6 & Nuclear staining in at least $10 \%$ of tumor cells. \\
\hline \multicolumn{6}{|l|}{$p 27$} \\
\hline & Oh [41] & 2001 & 49 & 46.9 & $\begin{array}{l}\text { Moderate or strong nuclear staining in more than } 10 \% \text { of } \\
\text { tumor cells. }\end{array}$ \\
\hline & Jirström [42] & 2003 & 92 & 68.5 & $\begin{array}{l}\text { Nuclear and cytoplasmic staining intensity were evaluated } \\
\text { using a } 3 \text {-point semiquantitative scoring scale }(0=\text { none, } \\
1=\text { weak, } 2=\text { moderate, } 3=\text { strong). }\end{array}$ \\
\hline & Millar [31] & 2007 & 60 & 55 & Nuclear staining in more than $50 \%$ of tumor cells. \\
\hline \multicolumn{6}{|l|}{$p 53$} \\
\hline & Albonico [7] & 1998 & 62 & $7.0-37.3$ & $\begin{array}{l}\text { Nuclear staining in more than } 5 \% \text { of tumor cells. } \\
37.3 \text { (comedo DCIS) } \\
17.2 \text { (noncomedo DCIS) } \\
\text { 7.0 (cribriform DCIS) }\end{array}$ \\
\hline & Bijker [10] & 2001 & 116 & 20 & On an 8-point scale, a score of at least 5. \\
\hline & Ringberg [16] & 2001 & 187 & 26 & Nuclear staining in more than $10 \%$ of tumor cells. \\
\hline & Hieken [48] & 2001 & 103 & 27 & Strong nuclear staining in more than $10 \%$ of tumor cells. \\
\hline & Wärnberg [36] & 2001 & 194 & 40 & Any p53 expression. \\
\hline & Oh [41] & 2001 & 49 & 30.6 & Nuclear staining in more than $5 \%$ of tumor cells. \\
\hline & Provenzano [22] & 2003 & 95 & 60 & $\begin{array}{l}\text { On a 6-point scale, a score of } 4-6 \text { (moderate or strong stain- } \\
\text { ing). }\end{array}$ \\
\hline & Lebeau [12] & 2003 & 45 & 25 & $\begin{array}{l}\text { Moderate or strong nuclear staining in more than } 40 \% \text { of } \\
\text { tumor cells. }\end{array}$ \\
\hline & Chasle [38] & 2003 & 50 & 88 & $\begin{array}{l}\text { The percentage of marked nuclei was determined for } \\
300-400 \text { nuclei in the most positive foci. }\end{array}$ \\
\hline & Roka [23] & 2004 & 190 & 57.2 & Nuclear staining in at least $10 \%$ of tumor cells. \\
\hline & Perrone [20] & 2005 & 49 & 26.5 & Nuclear staining in more than $10 \%$ of tumor cells. \\
\hline & Kepple [59] & 2006 & 94 & 50 & No cut-off value was mentioned in the paper. \\
\hline & Livasy [66] & 2007 & 245 & 31 & $\begin{array}{l}\text { Nuclear or nuclear and cytoplasmic staining in more than } \\
10 \% \text { of tumor cells. }\end{array}$ \\
\hline & Meijnen [14] & 2008 & 163 & 26 & Nuclear staining in more than $25 \%$ of tumor cells. \\
\hline & Okumura [52] & 2008 & 52 & 76.5 & Nuclear staining in more than $10 \%$ of tumor cells. \\
\hline & Kulkarni [21] & 2008 & 69 & 67.9 & Nuclear staining in at least $10 \%$ of tumor cells. \\
\hline & Kerlikowske [24] & 2010 & 329 & 11.3 & Nuclear staining in at least $10 \%$ of tumor cells. \\
\hline \multicolumn{6}{|l|}{$B c l-2$} \\
\hline & Albonico [7] & 1998 & 62 & $35.7-100$ & $\begin{array}{l}\text { Nuclear staining in more than } 10 \% \text { of tumor cells. } \\
35.7 \text { (comedo DCIS) } \\
100 \text { (noncomedo DCIS) } \\
100 \text { (cribriform DCIS) }\end{array}$ \\
\hline & Ringberg [16] & 2001 & 187 & 56 & Cytoplasm staining in more than $10 \%$ of tumor cells. \\
\hline & Wärnberg [36] & 2001 & 194 & 48 & Nuclear staining in at least $10 \%$ of tumor cells. \\
\hline & Provenzano [22] & 2003 & 95 & 50 & $\begin{array}{l}\text { On a 6-point scale, a score of } 4-6 \text { (moderate or strong stain- } \\
\text { ing). }\end{array}$ \\
\hline & Meijnen [14] & 2008 & 163 & 64 & Weak cytoplasmic staining in more than $10 \%$ of tumor cells. \\
\hline & Okumura [52] & 2008 & 52 & 58.8 & Nuclear staining in more than $5 \%$ of tumor cells. \\
\hline \multicolumn{6}{|l|}{ Bax } \\
\hline & Okumura [52] & 2008 & 52 & 71.2 & Nuclear staining in more than $5 \%$ of tumor cells. \\
\hline \multicolumn{6}{|l|}{ Survivin } \\
\hline & Barnes [54] & 2006 & 161 & $\begin{array}{l}10 \text { (nuclear } \\
\text { staining } \\
\text { alone); } \\
29 \% \text { (cyto- } \\
\text { plasmic } \\
\text { staining } \\
\text { alone); } \\
29 \% \text { (cyto- } \\
\text { plasmic and } \\
\text { nuclear } \\
\text { staining) }\end{array}$ & $\begin{array}{l}\text { Survivin staining was scored for both cytoplasmic and } \\
\text { nuclear staining. For cytoplasmic staining, a score of at least } \\
2 \text { was considered positive; for nuclear staining, the propor- } \\
\text { tion of positive cells out of at least } 1,000 \text { was determined. }\end{array}$ \\
\hline
\end{tabular}




\begin{tabular}{llllll}
\hline \multirow{2}{*}{ - -myc } & Okumura [52] & 2008 & 52 & 55.8 & Nuclear staining in more than 5\% of tumor cells. \\
$\mathrm{Rb}$ & Altintas [15] & 2009 & 159 & 60 & Score of at least 2. \\
& Okumura [52] & 2008 & 52 & 68.6 & Nuclear staining in more than 10\% of tumor cells. \\
\hline
\end{tabular}

Table 5. Expression rates of angiogenesis related proteins in DCIS

\begin{tabular}{|c|c|c|c|c|c|}
\hline Biomarker & $\begin{array}{l}\text { First author and } \\
\text { reference }\end{array}$ & Year & $\begin{array}{l}\text { No. of } \\
\text { samples }\end{array}$ & $\begin{array}{l}\text { Expression } \\
\text { rate, \% }\end{array}$ & Definition of positivity \\
\hline \multicolumn{6}{|c|}{ Vascular endothelial growth factor (VEGF) } \\
\hline & Hieken [48] & 2001 & 103 & 86 & $\begin{array}{l}\text { Cytoplasmic and/or membrane staining in more than } 10 \% \\
\text { of tumor cells. }\end{array}$ \\
\hline & Perrone [20] & 2005 & 49 & 93.8 & $\begin{array}{l}\text { Staining (defined as appropriate brown staining in the } \\
\text { tumor cell cytoplasm) in more than } 10 \% \text { of tumor cells. }\end{array}$ \\
\hline \multicolumn{6}{|c|}{ Heparanase-1 (HPR1) } \\
\hline & Maxhimer [56] & 2005 & 45 & 42.2 & Nuclear staining in more than $20 \%$ of tumor cells. \\
\hline
\end{tabular}

Table 6. Expression rates of human epidermal growth factor receptor (HER) family in DCIS

\begin{tabular}{|c|c|c|c|c|c|}
\hline Biomarker & $\begin{array}{l}\text { First author and } \\
\text { reference }\end{array}$ & Year & $\begin{array}{l}\text { No. of } \\
\text { samples }\end{array}$ & $\underset{\%}{\text { Expression rate, }}$ & Definition of positivity \\
\hline \multicolumn{6}{|c|}{ Human epidermal growth factor receptor 1 (HER1) } \\
\hline & Lebeau [12] & 2003 & 45 & 36.4 & $\begin{array}{l}\text { Any distinctive membrane staining of intraductal tumor } \\
\text { cells. }\end{array}$ \\
\hline & Bryan [65] & 2006 & 66 & 22 & $\begin{array}{l}\text { Any cytoplasmic and/or membranous staining of tumor } \\
\text { cells. }\end{array}$ \\
\hline & Altintas [15] & 2009 & 159 & 13 & Score of at least 2 \\
\hline \multicolumn{6}{|c|}{ HER2/neu (HER2) } \\
\hline & Albonico [7] & 1998 & 62 & $1.0-72.8$ & $\begin{array}{l}\text { Staining in more than } 10 \% \text { of tumor cells. } \\
72.8 \text { (comedo DCIS) } \\
10.8 \text { (noncomedo DCIS) } \\
1.0 \text { (cribriform DCIS) }\end{array}$ \\
\hline & Claus [9] & 2001 & 219 & 28 & On a 4-point scale, any score other than 0. \\
\hline & Bijker [10] & 2001 & 116 & 46.2 & Any expression. \\
\hline & Ringberg [16] & 2001 & 187 & 54 & Membrane staining in more than $10 \%$ of tumor cells. \\
\hline & Wärnberg [36] & 2001 & 194 & 55 & $\begin{array}{l}\text { Moderate or strong membrane staining in at least } 30 \% \text { of } \\
\text { tumor cells or complete membrane staining in more than } \\
60 \% \text { of tumor cells regardless of the intensity of the } \\
\text { staining. }\end{array}$ \\
\hline & Latta [57] & 2002 & 91 & 34.1 & $\begin{array}{l}\text { On an 8-point scale, an IHC score of at least } 5 \text {. In addition, } \\
\text { a HER2/CEP17 ratio of at least } 2 \text { was considered positive } \\
\text { for HER2/neu gene amplification. }\end{array}$ \\
\hline & DiGiovanna [17] & 2002 & 219 & 28 & On a 4-point scale, any score other than 0. \\
\hline & Hoque [73] & 2002 & 100 & 40 & $\begin{array}{l}\text { HER2 gene amplification was analyzed by FISH. A ratio } \\
\text { of greater than } 2.0 \text { was considered indicative of HER2 } \\
\text { gene amplification. }\end{array}$ \\
\hline & Provenzano [22] & 2003 & 95 & 32 & $\begin{array}{l}\text { Strong staining (equivalent to a score of } 3+\text { with the } \\
\text { DakoCytomation HercepTest). }\end{array}$ \\
\hline & Lebeau [12] & 2003 & 45 & 46.7 & $\begin{array}{l}\text { On a 3-point scale, a score of greater than } 2 \text {. Scoring was } \\
\text { based on the positive staining of the cell membrane. }\end{array}$ \\
\hline & Roka [23] & 2004 & 190 & 41.3 & Nuclear staining in more than $30 \%$ of tumor cells. \\
\hline & Boland [19] & 2004 & 187 & 54.5 & On a 3-point scale, a score of at least 2. \\
\hline & Barnes [35] & 2005 & 129 & 65 & Score of at least 2. \\
\hline & Perrone [20] & 2005 & 49 & 66.7 & $\begin{array}{l}\text { Complete membrane staining in more than } 10 \% \text { of tumor } \\
\text { cells. }\end{array}$ \\
\hline & Collins [13] & 2005 & 148 & 28 & $\begin{array}{l}\text { Strong membrane staining in more than } 10 \% \text { of tumor } \\
\text { cells (equivalent to a score of } 3+\text { with the DakoCytomation } \\
\text { HercepTest). }\end{array}$ \\
\hline
\end{tabular}




\begin{tabular}{|c|c|c|c|c|c|}
\hline & Bryan [65] & 2006 & 66 & 67 & $\begin{array}{l}\text { Membrane staining in more than } 10 \% \text { of tumor cells } \\
\text { (equivalent to a score of } 3+\text { in the DakoCytomation Her- } \\
\text { cepTest). All cases were high-nuclear-grade DCIS. }\end{array}$ \\
\hline & Kepple [59] & 2006 & 94 & 27 & No cut-off value was mentioned in the paper. \\
\hline & Wilson [37] & 2006 & 129 & 64.8 & On a 3-point scale, a score of at least 2. \\
\hline & Barnes [54] & 2006 & 161 & 64.7 & Score of at least 2. \\
\hline & Livasy [66] & 2007 & 245 & 25 & $\begin{array}{l}3+\text { intensity with DAB chromogen and } 2+\text { or } 3+\text { intensity } \\
\text { with the SG chromogen in more than } 10 \% \text { of tumor cells. }\end{array}$ \\
\hline & Meijnen [14] & 2008 & 163 & 39 & $\begin{array}{l}\text { Strong membranous staining in more than } 10 \% \text { of tumor } \\
\text { cells. }\end{array}$ \\
\hline & Hanley [8] & 2008 & 90 & $\begin{array}{l}9 \\
\text { (non-high-grade } \\
\text { DCIS); } \\
55 \text { (high-grade } \\
\text { DCIS) }\end{array}$ & Membrane staining of $3+$. \\
\hline & Tamimi [67] & 2008 & 272 & 27.2 & $\begin{array}{l}\text { Moderate or strong membrane staining ( } 2+\text { of higher on a } \\
\text { 3-point scale) in at least } 10 \% \text { of tumor cells. }\end{array}$ \\
\hline & Okumura [52] & 2008 & 52 & 17.3 & On a 3-point scale, a score of 3 (strong staining). \\
\hline & Kulkarni [21] & 2008 & 69 & 60.4 & $\begin{array}{l}\text { On a } 3 \text {-point scale, } 3+\text { staining in more than } 10 \% \text { of tumor } \\
\text { cells. }\end{array}$ \\
\hline & Roses [68] & 2009 & 84 & 28.6 & $\begin{array}{l}\text { Membranous staining of } 3+\text { in any tumor cell or mem- } \\
\text { branous staining of } 2+\text { in more than } 10 \% \text { of tumor cells } \\
\text { with fluorescence in situ hybridization evidence of HER2 } \\
\text { gene amplification. }\end{array}$ \\
\hline & Suzuki [69] & 2009 & 58 & 9 & $\begin{array}{l}\text { On a 3-point scale, a score of } 3 \text { or positive for HER2 gene } \\
\text { amplification when HER2/CEP17 greater than } 2.2 \text {. }\end{array}$ \\
\hline & Altintas [15] & 2009 & 159 & 40 & Score of at least 2. \\
\hline & Yu K [70] & 2010 & 271 & 33.7 & $\begin{array}{l}\text { Results of immunohistochemical assays were evaluated } \\
\text { using a proportion score and an intensity score. HER2 } \\
\text { status was defined as positive for scores of 9-12. }\end{array}$ \\
\hline & Stackievicz [74] & 2010 & 84 & 44 & $\begin{array}{l}\text { Moderate or strong membrane staining }(2+\text { or higher on a } \\
\text { 3-point scale) in more than } 10 \% \text { of tumor cells. }\end{array}$ \\
\hline & Kuerer [18] & 2010 & 69 & 35 & $\begin{array}{l}\text { On a 3-point scale, a } 3+\text { score was considered to be posi- } \\
\text { tive by IHC or positive for HER } 2 \text { gene amplification when } \\
\text { HER2/CEP17 ratio greater than } 2.0 \text { by FISH. }\end{array}$ \\
\hline & Bundred [30] & 2010 & 90 & 32 & $\begin{array}{l}\text { On a 3-point scale, a score of greater than } 2 \text {. All cases were } \\
\text { ER-positive DCIS. }\end{array}$ \\
\hline & Kerlikowske [24] & 2010 & 329 & 18.2 & $\begin{array}{l}\text { Moderate or strong membrane staining }(2+\text { or higher)in at } \\
\text { least } 10 \% \text { of tumor cells. }\end{array}$ \\
\hline & Behling [71] & 2010 & 65 & 50 & No cut-off value was mentioned in the paper. \\
\hline & Witkiewicz [61] & 2010 & 97 & 33.3 & Status obtained from pathology reports. \\
\hline & Holmes [58] & 2011 & 141 & 27.7 & On a 3-point scale, a score of 3. \\
\hline \multicolumn{6}{|l|}{ HER3 } \\
\hline & Barnes [35] & 2005 & 129 & 56 & Score of at least 2 . \\
\hline & Altintas [15] & 2009 & 159 & 62 & Score of at least 2. \\
\hline \multicolumn{6}{|l|}{ HER4 } \\
\hline & Barnes [35] & 2005 & 129 & 55 & Score of at least 2. \\
\hline & Altintas [15] & 2009 & 159 & 37 & Score of at least 2 . \\
\hline
\end{tabular}

FISH, fluorescence in situ hybridization; IHC, immunohistochemical.

Table 7. Expression rates of extracellular matrix-related proteins in DCIS

\begin{tabular}{lllllll}
\hline Biomarker & $\begin{array}{l}\text { First author and } \\
\text { reference }\end{array}$ & Year & $\begin{array}{l}\text { No. of } \\
\text { samples }\end{array}$ & $\begin{array}{l}\text { Expression } \\
\text { rate, \% }\end{array}$ & Definition of positivity \\
\hline CD10 & Toussaint [60] & 2010 & 154 & 27 & $\begin{array}{l}\text { CD10 scoring was based on expression and intensity values. } \\
\text { A high score was determined to be equivalent to 6. } \\
\text { On a 3-point scale, a score of 2 (defined as strong staining of } \\
\text { at least 30\% of stromal cells). }\end{array}$ \\
SPARC & Witkiewicz [61] & 2010 & 97 & 18.8 & $\begin{array}{l}\text { On a 3-point scale, a score of 2 (defined as strong staining of } \\
\text { at least 30\% of stromal cells). }\end{array}$ \\
\hline
\end{tabular}


Table 8. Expression rate of COX-2 in DCIS

\begin{tabular}{|c|c|c|c|c|c|}
\hline Biomarker & $\begin{array}{l}\text { First author and } \\
\text { reference }\end{array}$ & Year & $\begin{array}{l}\text { No. of } \\
\text { samples }\end{array}$ & $\begin{array}{l}\text { Expression } \\
\text { rate, \% }\end{array}$ & Definition of positivity \\
\hline & Tan [63] & 2004 & 51 & 80 & $\begin{array}{l}\text { On a 9-point scale, } 0 \text { was considered to be nil; } 1-3 \text { was con- } \\
\text { sidered to be mild; } 4-6 \text { was considered to moderate; } 7-9 \text { was } \\
\text { considered to be strong. Only unequivocal cytoplasmic } \\
\text { staining was regarded as positive. }\end{array}$ \\
\hline & Boland [19] & 2004 & 187 & 67 & $\begin{array}{l}\text { On a 3-point scale, a score of at least 2. Expression was } \\
\text { based on the extent and intensity of epithelial cell staining. }\end{array}$ \\
\hline & Perrone [20] & 2005 & 49 & 87.8 & $\begin{array}{l}\text { On a 12-point scale for immunoreactivity, an immuno- } \\
\text { histochemistry score of 9-12 was considered strong, 5-8 was } \\
\text { considered moderate, 1-4 was considered weak, and } 0 \text { was } \\
\text { considered negative. }\end{array}$ \\
\hline & Gauthier [62] & 2005 & 30 & 60.7 & No cut-off value was mentioned in the paper. \\
\hline & Barnes [54] & 2006 & 161 & 72 & Score of at least 2 . \\
\hline & Gauthier [45] & 2007 & 70 & 55.7 & Allred score of at least 2 . \\
\hline & Kulkarni [21] & 2008 & 69 & 45.8 & $\begin{array}{l}\text { Cytoplasmic granular staining in more than } 10 \% \text { of tumor } \\
\text { cells. }\end{array}$ \\
\hline & Bundred [30] & 2010 & 90 & 58 & $\begin{array}{l}\text { A minimum of } 500 \text { cells was investigated across randomly } \\
\text { selected areas of DCIS at a magnification of x } 400 \text { using a } \\
\text { grid graticule and cell counter for each of the two sections. } \\
\text { All cases were ER-positive DCIS. }\end{array}$ \\
\hline & de la Torre [64] & 2010 & 52 & 53 & On a 3-point scale, a score of at least 2. \\
\hline & Kerlikowske [24] & 2010 & 329 & 44.4 & On a 3-point scale, a score of at least 2. \\
\hline
\end{tabular}

Table 9. Biomarker expression and ipsilateral recurrence risk following surgery for DCIS

\begin{tabular}{lllllll}
\hline Biomarker $\begin{array}{l}\text { First author } \\
\text { and refer- } \\
\text { ence }\end{array}$ & Year & $\begin{array}{l}\text { No. of pa- } \\
\text { tients }\end{array}$ & Treatment groups & $\begin{array}{l}\text { Median } \\
\text { fol- } \\
\text { low-up } \\
\text { time, } \\
\text { months }\end{array}$ & $\begin{array}{l}\text { Endocrine } \\
\text { therapy }\end{array}$ & $\begin{array}{l}\text { Marker ex- } \\
\text { pression as- } \\
\text { sociated with } \\
\text { increased risk } \\
\text { of lo- } \\
\text { cal-regional } \\
\text { recurrence }\end{array}$ \\
\hline
\end{tabular}

\section{Steroid Receptors}

ER

\begin{tabular}{|c|c|c|c|c|c|c|c|}
\hline $\begin{array}{l}\text { Ringberg } \\
{[16]}\end{array}$ & 2001 & 187 & $\begin{array}{l}\text { Lumpectomy with } \\
\text { XRT-66; Lumpec- } \\
\text { tomy without } \\
\text { XRT-121 }\end{array}$ & 62 & No & $\begin{array}{l}\text { Yes (when } \\
\text { combined } \\
\text { with other } \\
\text { biological } \\
\text { markers) }\end{array}$ & $\begin{array}{l}\text { The investigators evaluated a cell } \\
\text { biological index (CBI-7) that in- } \\
\text { cluded ER and PR negativity, } \\
\text { overexpression of HER2, low Bcl-2 } \\
\text { expression, accumulation of p53, } \\
\text { nondiploidy, and high Ki-67 ex- } \\
\text { pression. ER negativity combined } \\
\text { with all those markers was a } \\
\text { strong predictor of recurrence (RR: } \\
1.3 ; 95 \% \text { CI: } 1.0-1.6 ; P=0.051) \text {. }\end{array}$ \\
\hline $\begin{array}{l}\text { Provenzano } \\
\text { [22] }\end{array}$ & 2003 & $\begin{array}{l}95 \text { ( } 53 \text { cases } \\
\text { and } 42 \text { con- } \\
\text { trols) }\end{array}$ & $\begin{array}{l}\text { Lumpectomy } \\
\text { without XRT-85; } \\
\text { Lumpectomy with } \\
\text { XRT -10 }\end{array}$ & 101 & Yes & Yes & $\begin{array}{l}\text { Patients with local-regional recur- } \\
\text { rence were more likely than pa- } \\
\text { tients without recurrence to have } \\
\text { ER-negative disease ( } 62 \% \text { vs. } 35 \% \text {; } \\
\text { OR: } 0.2 ; P=0.01) \text {. ER negativity was } \\
\text { individually associated with re- } \\
\text { currence. }\end{array}$ \\
\hline Roka [23] & 2004 & 190 & $\begin{array}{l}\text { Lumpectomy } \\
\text { without XRT-33; } \\
\text { Lumpectomy with } \\
\text { XRT-99; Mastec- } \\
\text { tomy with XRT-58 }\end{array}$ & 61.6 & Yes & Yes & $\begin{array}{l}\text { The recurrence rate was higher for } \\
\text { ER-negative DCIS than for } \\
\text { ER-positive DCIS ( } 12.2 \% \text { vs. } 3.7 \% \text {; } \\
P<0.04) \text {. }\end{array}$ \\
\hline $\begin{array}{l}\text { Cornfield } \\
\text { [46] }\end{array}$ & 2004 & 151 & $\begin{array}{l}\text { All patients were } \\
\text { treated with lum- } \\
\text { pectomy without }\end{array}$ & 65 & No & No & $\begin{array}{l}\text { ER was not associated with disease } \\
\text { recurrence in either univariate or } \\
\text { multivariate analysis. }\end{array}$ \\
\hline
\end{tabular}


Kepple [59] $2006 \quad 94$

Barnes [54] $2006 \quad 161$

Wilson [37] $2006 \quad 129$

de Roos [43] $2007 \quad 87$

Millar [31] $\quad 2007 \quad 60$

Kulkarni $\quad 2008 \quad 69$

[21]

Altintas [15] $2009 \quad 159$

Kerlikow- 2010329 ske [24]

Witkiewicz $2010 \quad 97$ [61]

Holmes [58] $2011 \quad 141$
$48 \quad$ Yes Unknown $\begin{array}{ll}\text { Lumpectomy-89; } & \text { Not } \\ \text { Mastectomy -40 } & \text { pro- } \\ \text { (8 patients received } & \text { vided }\end{array}$ XRT)

Lumpectomy

without XRT - 17;

Lumpectomy with

XRT - 20; Mastec-

tomy -57 months

No

No

(1) with no recurrence, 186;

cases with invasive recurrence, 72 cases with rence, 71 )
Lumpectomy - 103;

Mastectomy - 47;

Information una-

vailable for $11 \mathrm{pa}$

tients. No infor-

mation available on XRT

Patients underwent definitive surgery for DCIS, but no details were provided

Lumpectomy - 39;

Mastectomy -48

(21 patients received XRT)

Lumpectomy with

or without XRT -56

(51 received XRT)

Mastectomy without XRT - 4

Lumpectomy
without XRT-26;
Lumpectomy with XRT -43

Lumpectomy -112;

Mastectomy -45

Information una-

vailable for 2 pa-

tients. No infor-

mation available on XRT

All patients were treated with lumpectomy alone

Not

pro-

vided

Unknown No

Not

pro-

vided

No

No

49.8

No

No

98

No No

Mean Yes No

time to

recur-

rence:

38.5

$54 \quad$ No No

98

No

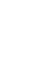
DCIS recur-

\section{Zhou [25] $2010392 \quad \begin{aligned} & \text { Lumpectomy } \\ & \text { without XRT -158; }\end{aligned}$ Lumpectomy with XRT - 140; Mastec- tomy -94}

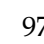

Yes (when combined with other biomarkers)
In the univariate analysis, patients with DCIS recurrence were more likely than those without recurrence to have ER-negative disease ( $31 \%$ vs. $20 \%$ ). ER negativity was individually associated with DCIS recurrence. In addition, ER negativity combined with either HER2 positivity or Ki-67 positivity was also associated with DCIS recurrence. In the multivariate analysis, the phenotype ER-HER2+Ki-67+ was a strong predictor of subsequent DCIS recurrence (HR: 5.8; 95\% CI: 2.4-14).

The investigators looked at basal-like tumors (tumors negative for ER, PR, and HER2). In the univariate and multivariate analyses, basal-like DCIS was associated with a higher risk of invasive recurrence than non-basal-like DCIS. However, the difference was not statistically significant.

The investigators did not find ER to be an independent predictor of recurrence. no information was available about XRT

All patients underwent lumpectomy alone
110.8 No No

125
No No
In the univariate and multivariate analyses, ER was not a predictor of recurrence. 

XRT - 66; Lumpectomy without XRT-121
Lumpectomy with
Ringberg $2001 \quad 187$
62

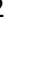

$\begin{array}{ll}\text { No } & \text { Yes (when } \\ \text { combined } \\ \text { with other } \\ \text { biological } \\ \text { markers) }\end{array}$

Provenzano 200395

[22]

$\begin{array}{lll}\text { Roka [23] } & 2004 & 190 \\ & & \\ \begin{array}{l}\text { Cornfield } \\ \text { [46] }\end{array} & 2004 & 151 \\ \text { Kepple [59] } & 2006 & 94\end{array}$

de Roos [43] $2007 \quad 87$

Millar [31] $\quad 2007 \quad 60$

Kulkarni $\quad 2008 \quad 69$

[21]

Altintas [15] $2009 \quad 159$

Zhou [25] $\quad 2010 \quad 392$
Lumpectomy

without XRT - 85;

Lumpectomy with

XRT -10

Lumpectomy

without XRT - 33.

Lumpectomy with

XRT - 99; Mastec-

tomy with XRT -58

All patients were treated with lumpectomy alone

Lumpectomy
without XRT-17;
Lumpectomy with
XRT-20; Mastec-
tomy - 57

$48 \quad$ Yes Unknown

months

Lumpectomy - 39;

Mastectomy -48

(21 patients received XRT)

Lumpectomy with

or without XRT -56

(51 received XRT);

Mastectomy without XRT - 4

Lumpectomy
without XRT -26;
Lumpectomy with
XRT - 43

$61.6 \quad$ Yes $\quad$ No

65

No

No

$98 \quad$ No $\quad$ No

Mean Yes No

time to

recur-

rence:

38.5

Lumpectomy -112; 54

mastectomy -45

Information una-

vailable for 2 pa-

tients. No inforXRT

Lumpectomy
without XRT-158;
Lumpectomy with

XRT - 140; Mastec-

tomy -94
No

No

97.5

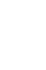

mation available on
The investigators evaluated a cell biological index (CBI-7) that included ER and PR negativity, overexpression of HER2, low Bcl-2 expression, accumulation of p53, nondiploidy, and high Ki-67 expression. PR negativity combined with all those markers was a strong predictor of recurrence (RR: 1.3; 95\% CI: $1.0-1.6 ; P=0.051)$.

Patients with local-regional recurrence were more likely than those without recurrence to have

PR-negative disease (63\% vs. $34 \%$; OR: $0.2 ; P=0.04)$. PR negativity was individually associated with recurrence.

PR-negative DCIS was associated with a higher rate of recurrence than PR-positive DCIS $(9.1 \%$ vs. $3.6 \%$ ), but this difference did not reach statistical significance.

PR was not associated with disease recurrence in either univariate or multivariate analysis.

Difficult to assess effect. Only 37 patients underwent lumpectomy, and there were only 4 recurrences in that group. Some of those 37 patients received radiotherapy and some did not.

PR was not associated with disease recurrence in either univariate or multivariate analysis.

In the univariate analysis conducted with clinicopathological parameters, PR was not associated with disease recurrence.

The investigators concluded that the biological marker, $\mathrm{PR}$, is not an independent predictor of recurrence.

The investigators concluded that the biological marker, $\mathrm{PR}$, is not an independent predictor of recurrence.

The investigators looked at basal-like tumors (tumors negative for ER, PR, and HER2). In the univariate and multivariate analyses, basal-like DCIS was associated with a higher risk of local recurrence (HR: 1.7) than non-basal-like DCIS (HR: 1.8). However, the difference was not statistically significant.

PR was not associated with invasive or DCIS recurrence in either univariate or multivariate analysis. with no recases with invasive recurrence, 72 cases with

DCIS recurrence, 71 )

Witkiewicz $2010 \quad 97$ [61]

The investigators did not find PR to be an independent predictor of recurrence. 
available about

XRT)

Holmes [58] 2011141

AR

Provenzano 200395

[22]

\section{Proliferation marker Ki-67}

$\begin{array}{lll}\text { Ringberg } & 2001 \quad 187 \\ \text { [16] }\end{array}$

Chasle [38] $2003 \quad 50$

$\begin{array}{lll}\begin{array}{l}\text { Cornfield } \\ \text { [46] }\end{array} & 2004 & 151 \\ & & \\ \text { Barnes [35] } & 2005 & 129\end{array}$

Wilson [37] $2006 \quad 129$

Barnes [54] $2006 \quad 161$

Gauthier $\quad 2007 \quad 70$

[45]

Altintas [15] $2009 \quad 159$

Kerlikow- 2010329 ske [24]

(Controls with no recurrence, 186;
All patients underwent lumpectomy alone

125

Lumpectomy

without XRT -85 .

Lumpectomy with XRT -10

Lumpectomy with XRT - 66; Lumpectomy without

XRT - 121

All patients underwent lumpectomy followed by XRT

All patients were treated with lumpectomy alone

Lumpectomy - 89; Mastectomy -40 (8 patients received XRT)

Patients underwent definitive surgery for DCIS, but no details were provided

Lumpectomy - 103; Mastectomy -47; Information unavailable for 11 patients. No information available on XRT

Patients underwent Not Unknown Yes (as an definitive surgery profor DCIS, but no $\quad$ vided details were provided

Lumpectomy - 112; mastectomy -45 Information unavailable for 2 patients. No information available on XRT

$\begin{array}{llll}\text { All patients were } & 98 & \text { No } & \text { Yes }\end{array}$ treated with lumpectomy alone 65

Unknown

No

Yes (when combined with cyclin A)

No

Yes provided

\section{Not} pro-
vided

No

No

Not

pro-

Unknown Yes independent factor and combined with p16 expression and COX-2 expression)

54

No

No
PR was not associated with disease recurrence in either univariate or multivariate analysis.

The investigators did not find AR to be associated with disease recurrence.

The investigators evaluated a cell biological index (CBI-7) that included ER and PR negativity, overexpression of HER2, low Bcl-2 expression, accumulation of p53, nondiploidy, and high $\mathrm{Ki}-67 \mathrm{ex}-$ pression. High Ki-67 expression combined with all those markers was a strong predictor of recurrence (RR: 1.3; 95\% CI: 1.0-1.6; $P=0.051)$.

A global proliferation factor (GPF) was calculated that was a sum of Ki-67 and cyclin A. In both univariate and multivariate analyses, GPF was an independent predictor of recurrence.

Ki-67 was not associated with disease recurrence in either univariate or multivariate analysis.

Patients with recurrence were more likely than patients without recurrence to have high proliferative activity $(15.5 \%$ vs. $10.9 \%$; $P=0.005)$. In the multivariate anal ysis, Ki-67 was an independent predictor of recurrence (OR: 1.03, 95\% CI: $1.00-1.06 ; P=0.038$ )

In the univariate analysis, patients with recurrence were more likely than patients without recurrence to have high proliferative activity compared to patients without a recurrence (71.4 vs. $42.2 \%$, $P=0.006)$. However, in the multivariate analysis, $\mathrm{Ki}-67$ was not an independent predictor of recurrence.

In the multivariate analysis, $\mathrm{Ki}-67$ was an independent predictor of recurrence (OR: $1.03,95 \% \mathrm{CI}$ : $1.00-1.06 ; P=0.006)$.

High Ki-67 expression was an independent predictor of recurrence (HR: 2.7, 95\% CI: 1.2-5.9). In addition, patients with recurrence were more likely than patients without recurrence to have the combination of high $\mathrm{Ki}-67$, high p16, and high COX-2 expression.

The investigators concluded that the biological marker, Ki67, is not an independent predictor of recurrence.

In the univariate analysis, patients with invasive recurrence were more likely than those without recurrence to exhibit the pheno- 
cases with invasive recurrence, 72 cases with DCIS recurrence, 71 )

Cell Cycle Regulation and Apoptotic Markers cyclin D1

\begin{tabular}{|c|c|}
\hline $\begin{array}{l}\text { Jirström } \\
\text { [42] }\end{array}$ & 2003 \\
\hline Chasle [38] & 2003 \\
\hline de Roos [43] & 2007 \\
\hline Millar [31] & 2007 \\
\hline $\begin{array}{l}\text { Kulkarni } \\
\text { [21] }\end{array}$ & 2008 \\
\hline
\end{tabular}

cyclin A

Chasle [38] $2003 \quad 50$

Millar [31] $2007 \quad 60$

cyclin E

Jirström
[42]

p16

$\begin{array}{lll}\begin{array}{l}\text { Jirström } \\ {[42]}\end{array} & 2003 & 177 \\ & & \\ \begin{array}{l}\text { Gauthier } \\ {[45]}\end{array} & 2007 & 70\end{array}$

[45]

Kerlikow- 2010329 ske [24]

$\begin{array}{llll}\begin{array}{l}\text { Lumpectomy } \\ \text { without XRT-64; } \\ \text { Lumpectomy with } \\ \text { XRT-113 }\end{array} & 63 & \text { No } & \text { Yes } \\ \begin{array}{l}\text { All patients under- } \\ \text { went lumpectomy } \\ \text { followed by XRT }\end{array} & \begin{array}{l}\text { Un- } \\ \text { known }\end{array} & \text { No } & \text { No } \\ \begin{array}{l}\text { Lumpectomy-39; } \\ \text { Mastectomy-48 } \\ \text { (21 patients re- }\end{array} & 49.8 & \text { No } & \text { No } \\ \text { ceived XRT) } & & & \\ \begin{array}{l}\text { Lumpectomy with } \\ \text { or without XRT-56 } \\ \text { (51 received XRT); }\end{array} & & \text { No } & \text { No } \\ \begin{array}{l}\text { Mastectomy with- } \\ \text { out XRT-4 }\end{array} & & & \\ \begin{array}{l}\text { Lumpectomy } \\ \text { without XRT-26; }\end{array} & \begin{array}{l}\text { Mean } \\ \text { time to }\end{array} & \text { Yes } & \text { No } \\ \begin{array}{l}\text { Lumpectomy with } \\ \text { XRT-43 }\end{array} & \begin{array}{l}\text { recur- } \\ \text { rence: }\end{array} & & \\ & 38.5 & & \end{array}$
went lumpectomy followed by XRT

Lumpectomy with or without XRT -56 (51 received XRT); Mastectomy without XRT - 4

$$
\begin{aligned}
& \text { Lumpectomy } \\
& \text { without XRT-64; } \\
& \text { Lumpectomy with }
\end{aligned}
$$$$
\text { XRT -113 }
$$

Lumpectomy without XRT - 64; Lumpectomy with XRT - 113

Patients underwent definitive surgery for DCIS, but no details were provided

98 No No

63

No

No

63

No

No

Not

pro-

Unknown Yes (when combined with high COX-2 expression and high Ki-67 expression)

All patients were treated with lumpectomy alone type $166^{+} \mathrm{COX}-2^{+} \mathrm{Ki}-67^{+}$or p16 ${ }^{+} \mathrm{Ki}-67^{+}$. Ki-67 was individually associated with DCIS recurrence. In addition, patients with DCIS recurrence were more likely to have ER-Ki- $67^{+}$or

p16 ${ }^{+}$COX-2-Ki- $67^{+}$disease than were patients without recurrence. In the multivariate analysis, the phenotype $\mathrm{p} 16^{+} \mathrm{COX}-2^{+} \mathrm{Ki}-67^{+}$was a strong predictor of invasive recurrence (HR: 2.2; 95\% CI:

1.1-4.5). Phenotypes

p16+COX-2+Ki-67+(HR: 3.7; 95\% CI: $1.7-7.9)$ and ER-HER2 ${ }^{+} \mathrm{Ki}-67^{+}$ (HR: 5.8, 95\% CI: 2.4-14) were strong predictors of DCIS recurrence.

The investigators reported cyclin D1 expression to be strongly and inversely related with risk of ipsilateral local recurrence.

Cyclin D1 was not a predictor of recurrence in either univariate or multivariate analysis.

Cyclin D1 was not associated with disease recurrence in either univariate or multivariate analysis.

In the univariate analysis conducted with clinicopathological parameters, cyclin D1 was not associated with disease recurrence.

The investigators concluded that the biological marker, cyclin D1, is not an independent predictor of recurrence.

A global proliferation factor (GPF) was calculated that was a sum of $\mathrm{Ki}-67$ and cyclin A. In the univariate and multivariate analyses, GPF was an independent predictor of recurrence.

In the univariate analysis conducted with clinicopathological parameters, cyclin A was not associated with disease recurrence.

The investigators concluded that the biological marker, cyclin E, is not an independent risk factor for recurrence.

The investigators concluded that the biological marker, p16, is not an independent risk factor for recurrence.

Patients with recurrence were more likely than patients without recurrence to have the combination of high Ki-67, high p16, and high COX-2 expression.

In the univariate analysis, patients with invasive recurrence were more likely than those without recurrence to have p16-positive disease ( $57 \%$ vs. $30 \%)$. p16 positiv- 
invasive recurrence, 72; cases with DCIS recurrence, 71)329 patients

ity combined with Ki-67 positivity and COX-2 positivity was also associated with invasive recurrence. p16 was individually associated with invasive recurrence. In addition, $\mathrm{p} 16$ positivity combined with Ki-67 positivity and COX-2 negativity was associated with DCIS recurrence. In the multivariate analysis, the phenotype p $16^{+} \mathrm{COX}-2^{+} \mathrm{Ki}-67^{+}$was a strong predictor of invasive recurrence (HR: 2.2; 95\% CI: 1.1-4.5). Also, the phenotype $16^{+} \mathrm{COX}-2-\mathrm{Ki}-67^{+}$was a strong predictor of DCIS recurrence (HR: 3.7; 95\% CI: 2.4-14).

p21

Provenzano $2003 \quad 95$ [22]

Chasle [38] $2003 \quad 50$

\begin{tabular}{lll}
$\begin{array}{l}\text { Cornfield } \\
{[46]}\end{array}$ & 2004 & 151 \\
& & \\
$\begin{array}{l}\text { Kulkarni } \\
{[21]}\end{array}$ & 2008 & 69 \\
\hline & &
\end{tabular}

p27

$\begin{array}{lll}\text { Millar [31] } & 2007 & 60 \\ & & \\ & & \\ \begin{array}{l}\text { Jirström } \\ {[42]}\end{array} & 2003 & 177\end{array}$

p53
Lumpectomy Lumpectomy with XRT -10 without XRT -85 .

$101 \quad$ Yes Yes

All patients under- Un- $\quad$ No $\quad$ No went lumpectomy known followed by XRT All patients were
treated with lumpectomy alone

Lumpectomy without XRT - 26; Lumpectomy with XRT -43

Lumpectomy with or without XRT -56 (51 received XRT); Mastectomy without XRT - 4

Lumpectomy without XRT - 64. Lumpectomy with XRT - 113

Lumpectomy without XRT - 34; Lumpectomy with XRT - 41; Mastectomy -28

Lumpectomy with XRT - 66; Lumpectomy without XRT - 121

65

No

Mean

time to

recur-

rence:

38.5

98

No

No

63

No

No

58
(mean
fol-

fol-

time) $\begin{array}{lll}\text { Ringberg } & 2001 & 187\end{array}$ $\begin{array}{lll}\begin{array}{l}\text { Provenzano } \\ {[22]}\end{array} & \begin{array}{l}95(53 \text { cases } \\ \text { and } 42 \text { con- } \\ \text { trols })\end{array}\end{array}$

Chasle [38] $2003 \quad 50$

without XRT - 85;
Lumpectomy

Lumpectomy with XRT -10

All patients underwent lumpectomy followed by XRT
62 No Yes (when combined with other biological markers)

101 Yes No

Un- No No

known
Patients with local-regional recurrence were more likely than those without recurrence to have

p21-positive disease (54\% vs. $15 \%$; OR: $6.0 ; P=0.01$ ). p21 positivity was individually associated with recurrence. According to the multiple conditional logistic regression analysis, p21 expression was an independent predictor of recurrence (OR range: 4.31-6.54).

According to univariate and multivariate analyses, p21 was not observed to be an independent predictor of recurrence.

p21 was not associated with disease recurrence in either univariate or multivariate analysis.

The investigators concluded that the biological marker, p21, is not an independent predictor of recurrence.

In the univariate analysis conducted with clinicopathological parameters, p27 was not associated with disease recurrence.

The investigators concluded that the biological marker, p27, is not an independent risk factor for recurrence.

p53 was expressed in $63 \%$ of patients with recurrence and $24 \%$ of patients without recurrence $(P=0.03)$. The investigators concluded that strong p53 expression is associated with ipsilateral tumor recurrence.

The investigators evaluated a cell biological index (CBI-7) that included ER and PR negativity, overexpression of HER2, low Bcl-2 expression, accumulation of p53, nondiploidy, and high Ki-67 expression. High p53 expression combined with all those markers was a strong predictor of recurrence (RR: 1.3; 95\% CI: 1.0-1.6; $P=0.051$ ).

The investigators did not find p53 to be associated with disease recurrence.

p53 was not an independent predictor of recurrence in either univariate or multivariate analysis. 


\begin{tabular}{|c|c|c|}
\hline $\begin{array}{l}\text { Cornfield } \\
{[46]}\end{array}$ & 2004 & 151 \\
\hline Roka [23] & 2004 & 190 \\
\hline Kepple [59] & 2006 & 94 \\
\hline de Roos [43] & 2007 & 87 \\
\hline $\begin{array}{l}\text { Kulkarni } \\
\text { [21] }\end{array}$ & 2008 & 69 \\
\hline $\begin{array}{l}\text { Kerlikow- } \\
\text { ske [24] }\end{array}$ & 2010 & $\begin{array}{l}329 \\
\text { (Controls } \\
\text { with no re- } \\
\text { currence, 186; } \\
\text { cases with } \\
\text { invasive re- } \\
\text { currence, 72; } \\
\text { cases with } \\
\text { DCIS recur- } \\
\text { rence, 71) }\end{array}$ \\
\hline
\end{tabular}

Bcl-2

$\begin{array}{lll}\text { Ringberg } & 2001 & 187\end{array}$

$\begin{array}{lll}\begin{array}{l}\text { Provenzano } \\ {[22]}\end{array} & 2003 & 95 \\ & & \\ \begin{array}{l}\text { Cornfield } \\ {[46]}\end{array} & 2004 & 151\end{array}$

Survivin

Barnes [54] $2006 \quad 161$

c-myc

Altintas [15] $2009 \quad 159$

Angiogenesis-related proteins

VEGF

Hieken [48] $2001 \quad 103$

All patients were treated with lumpectomy without XRT

Lumpectomy without XRT - 33; XRT-99; Mastectomy and XRT -58

Lumpectomy Lumpectomy with XRT - 20; Mastectomy -57

Lumpectomy - 39; Mastectomy -48 (21 patients received XRT)

Lumpectomy without XRT-26; Lumpectomy with XRT -43

All patients were treated with lumpectomy alone Lumpectomy with without XRT -17;

Lumpectomy with XRT - 66; Lumpectomy without XRT-121

\begin{tabular}{|c|c|c|}
\hline 65 & No & No \\
\hline 61.6 & Yes & No \\
\hline $\begin{array}{l}48 \\
\text { months }\end{array}$ & Yes & Unknown \\
\hline 49.8 & No & Yes \\
\hline $\begin{array}{l}\text { Mean } \\
\text { time to } \\
\text { recur- } \\
\text { rence: } \\
38.5\end{array}$ & Yes & No \\
\hline 98 & No & No \\
\hline
\end{tabular}

$\begin{array}{ll}62 \quad \text { No } & \begin{array}{l}\text { Yes (when } \\ \text { combined } \\ \text { with other } \\ \text { biological } \\ \text { markers) }\end{array}\end{array}$

Lumpectomy

without XRT - 85;

Lumpectomy with XRT -10

All patients were treated with lumpectomy alone

Lumpectomy-103; Not Mastectomy-47; proInformation una- $\quad$ vided vailable for 11 patients. No information available on XRT

\footnotetext{
Lumpectomy-112; 54

Mastectomy -45

Information unavailable for 2 patients. No information available on XRT
}

p53 was not associated with disease recurrence in either univariate or multivariate analysis.

The investigators did not find p53 to be an independent predictor of disease recurrence.

Difficult to assess effect. Only 37 patients underwent lumpectomy, and there were only 4 recurrences in that group. Some of those 37 patients received radiotherapy and some did not.

p53 was an independent predictor of disease recurrence in multivariate (HR: 3.0, 95\% CI: 1.1-8.2

$P=0.036)$ and univariate (HR: 3.5 , $95 \%$ CI: $1.3-9.3, P=0.014)$ analyses.

The investigators concluded that the biological marker, p53, is not an independent predictor of recurrence.

p53 was not associated with invasive or DCIS recurrence either individually or when combined with other phenotypes.
$101 \quad$ Yes Yes

$65 \quad$ No No

The investigators evaluated a cell biological index (CBI-7) that included ER and PR negativity, overexpression of HER2, low Bcl-2 expression, accumulation of p53, nondiploidy, and high Ki-67 expression. Low Bcl-2 expression combined with all those markers was a strong predictor of recurrence (RR: 1.3; 95\% CI: 1.0-1.6; $P=0.051$ ).

Patients with local-regional recurrence were more likely than those without recurrence to have Bcl-2-negative disease (66\% vs. 26\%; P=0.003; OR: 0.18).

Bcl-2 was not associated with disease recurrence in either univariate or multivariate analysis.

Unknown Yes (not as an independent factor, but when combined with COX-2 expression)

$54 \quad$ No No

Patients with recurrence were more likely than those without recurrence to have co-expression of COX-2 and cytoplasmic survivin_(70\% vs. $41 \% ; P=0.013)$.

The investigators concluded that the biological marker, c-myc, is not an independent predictor of recurrence.

\begin{tabular}{llllllll} 
Hieken [48] & 2001 & 103 & Lumpectomy & 58 & Yes & No & The investigators did not find \\
\hline
\end{tabular}


Epidermal Growth Factor Receptor Family HER1

Barnes [35] $2005 \quad 129$

Altintas [15] $2009 \quad 159$

HER2

Ringberg $\quad 2001 \quad 187$

[16]

Provenzano 200395 [22]

Roka [23] 2004190

Cornfield $\quad 2004 \quad 151$

[46]

Barnes [35] $2005 \quad 129$

Barnes [54] $2006 \quad 161$

Kepple [59] $2006 \quad 94$

de Roos [43] $2007 \quad 87$

Kulkarni $\quad 2008 \quad 69$

[21]

Altintas [15] $2009 \quad 159$ wimpectomy

without XRT - 26;
Lumpectomy with

XRT -43

without XRT - 34;

Lumpectomy with

XRT - 41; Mastec-

tomy -28

(mean

fol-

low-up

time)

Lumpectomy -89;

5 years

Mastectomy -40

(8 patients received

XRT)

Lumpectomy -112

mastectomy -45

Information una-

vailable for 2 pa-

tients. No infor-

mation on XRT

Lumpectomy with

XRT - 66; Lumpec-

tomy without

XRT-121

Lumpectomy

without XRT - 85;

Lumpectomy with

XRT - 10

Lumpectomy

without XRT-33;

Lumpectomy with

XRT - 99; Mastec-

tomy with XRT -58

All patients were treated with lumpectomy alone

Lumpectomy -89

(8 patients received XRT)

Lumpectomy - 103; Mastectomy - 47;

Information una-

vailable for $11 \mathrm{pa}-$

tients. No infor-

mation available on

XRT

Lumpectomy
without XRT-17;
Lumpectomy with

XRT - 20; Mastec-

tomy -57

Lumpectomy - 39;

Mastectomy -48

(21 patients re-

ceived XRT)

Lumpectomy-112.

mastectomy -45

Information una-

vailable for 2 pa-

tients. No infor-

mation available on
VEGF to be an independent predictor of disease recurrence.

The investigators concluded that the biological marker, HER1, is not an independent predictor of recurrence.

The investigators concluded that the biological marker, HER1, is not an independent predictor of recurrence.
62 No Yes (when combined with other biological markers)

101 Yes $\quad$ Yes

61.6 Yes No

65

No

No

Not

pro-

Unknown No

vided

48 Yes Unknown

months

Yes

49.8

No

No

Mean Yes No

time to

recur-

rence:

58.

No

No
5 years Unknown No

The investigators evaluated a cell biological index (CBI-7) that included ER and PR negativity, overexpression of HER2, low Bcl-2 expression, accumulation of p53, nondiploidy, and high Ki-67 expression. HER2 positivity combined with all those markers was a strong predictor of recurrence (RR: 1.3; 95\% CI: 1.0-1.6; $P=0.051$ )

Patients with local-regional recurrence were more likely than those without recurrence to have HER2-positive disease (41\% vs. $12 \%$; OR: $5.0 ; P=0.008$ ).

The investigators did not find HER2 to be an independent predictor of disease recurrence.

HER2 was not associated with disease recurrence in either univariate or multivariate analysis.

The investigators concluded that the biological marker, HER2, is not an independent predictor of recurrence.

HER2 was not associated with disease recurrence in multivariate analysis.

Difficult to assess effect. Only 37 patients underwent lumpectomy, and there were only 4 recurrences in that group. Some of those 37 patients received radiotherapy and some did not.

HER2 overexpression was associated with recurrence in univariate analysis (HR: 3.1, 95\% CI: 1.1-8.7 $P=0.032$ ). However, multivariate analysis did not show HER2 overexpression to be an independent predictor of recurrence.

The investigators concluded that the biological marker, HER2, is not an independent predictor of recurrence.

The investigators concluded that the biological marker, HER2, is not an independent predictor of recurrence. 


$\begin{array}{lrl}\begin{array}{l}\text { Stackievicz } \\ \text { [74] }\end{array} & 2010 & 84 \\ \begin{array}{l}\text { Kerlikow- } \\ \text { ske [24] }\end{array} & & \\ & & \begin{array}{l}329 \\ \text { (Controls } \\ \text { with no re- } \\ \text { currence, 186; } \\ \text { cases with } \\ \text { invasive re- } \\ \text { currence, 72; } \\ \text { cases with } \\ \text { DCIS recur- } \\ \text { rence, 71) }\end{array} \\ & \end{array}$

Zhou [25] 2010392

Witkiewicz $2010 \quad 97$

[61]

Holmes [58] 2011141

HER3

Barnes [35] $2005 \quad 129$

Altintas [15] $2009 \quad 159$

HER4

Barnes [35] $2005 \quad 129$

Altintas [15] $2009 \quad 159$

Extracellular matrix-related proteins CD10

$\begin{array}{lll}\text { Toussaint } & 2010 \quad 154\end{array}$

\section{XRT}

Lumpectomy - 80

94.8

Yes

No ceived XRT); Mastectomy -4

All patients were treated with lumpectomy alone

98

No

Yes (43 patients re-
Lumpectomy without XRT - 158, Lumpectomy with XRT - 140; Mastectomy -94

$97.5 \quad$ No No

All patients under-

110.8

No

No went lumpectomy (no information was available about XRT)

All patients underwent lumpectomy 125 alone
The investigators concluded that the biological marker, HER2, is not an independent risk factor for recurrence.

In the univariate analysis, patients with DCIS recurrence were more likely than patients without recurrence to have HER2-positive disease ( $30 \%$ vs. $13 \%$ ). HER2 was individually associated with DCIS recurrence. Also, patients with DCIS recurrence were more likely than patients without recurrence to exhibit the ER-HER2+ phenotype $(19 \%$ vs. $6.4 \%)$. In addition, a multivariate analysis showed that the phenotype ER-HER2 ${ }^{+} \mathrm{Ki}-67^{+}$was a strong predictor of subsequent DCIS recurrence (OR: $5.8 ; 95 \% \mathrm{CI}$ : 2.4-14).

The investigators looked at basal-like tumors (tumors negative for ER, PR, and HER2). In the univariate and multivariate analyses, basal-like DCIS was associated with a higher risk of local recurrence (HR: 1.7) than non-basal-like DCIS (HR: 1.8). However, the difference was not statistically significant. (Note: The authors do not state in the paper how many patients with basal-like DCIS developed a recurrence - they only report HRs in the tables.)

The investigators did not find HER2 to be an independent predictor of recurrence.

Univariate analysis with respect to time to recurrence found HER2 overexpression to be associated with local recurrence $(P=0.028)$. In the multivariate analysis, HER2 overexpression was an independent predictor of disease recurrence (HR: 1.82, 95\% CI: 1.03-3.22, $P=0.041$ ).

The investigators concluded that the biological marker, HER3, is not an independent predictor of recurrence.

Mastectomy-40

(8 patients received XRT)

Lumpectomy-112; $54 \quad$ No No mastectomy -45

Information unavailable for 2 patients. No information on XRT

Lumpectomy-89; 5 years Unknown Yes Mastectomy -40 (8 patients received XRT)

Lumpectomy-112; $54 \quad$ No $\quad$ No mastectomy -45 Information unavailable for 2 patients. No information on XRT
The investigators concluded that the biological marker, HER3, is not an independent predictor of recurrence.
The investigators concluded that HER4 expression is an independent predictor of a reduced risk of recurrence (OR: 0.69, 95\% CI: $0.48-0.98, P=0.038$ ).

The investigators concluded that the biological marker, HER4, is not an independent predictor of recurrence.

Surgical infor-

6 years Yes

Yes

According to the multivariate 
[60]

Witkiewicz $2010 \quad 97$ [61]

SPARC

Witkiewicz $2010 \quad 97$ [61]

Gauthier $\quad 2007 \quad 70$

[45]

Kulkarni $\quad 2008 \quad 69$

[21]

$\begin{array}{lll}\begin{array}{l}\text { Kerlikow- } \\ \text { ske [24] }\end{array} & 2010 & 329 \\ & \text { (Controls } \\ & \text { with no re- } \\ & \text { currence, 186; } \\ & \text { cases with } \\ \text { invasive re- } & \text { currence, 72; } \\ & \text { cases with } \\ & \text { DCIS recur- } \\ & \text { rence, 71) }\end{array}$

mation was report-

ed according to

VNPI. $58 \%$ of pa-

tients with low

VNPI were treated

with lumpectomy

alone; $41 \%$ of those

with intermediate

VNPI received XRT

following lumpec-

tomy; $81 \%$ of pa-

tients with high

VNPI underwent mastectomy

All patients underwent lumpectomy

(no information was

available about

XRT)

$110.8 \quad$ No $\quad$ Yes

All patients underwent lumpectomy (no information was available about XRT)

No

Yes

Lumpectomy - 103

Mastectomy - 47;

Information una-

vailable for $11 \mathrm{pa}$ -

tients. No infor-

mation available on

XRT

Patients underwent Not Unknown Yes (when $\begin{array}{ll}\text { definitive surgery } & \text { pro- } \\ \text { for DCIS, but no } & \text { vided }\end{array}$ details were provided

Lumpectomy without XRT - 26; Lumpectomy with XRT -43

All patients were treated with lumpectomy alone pro-

Unknown Yes (as an independent factor and in combination with survivin) combined with high p16 expression and high Ki-67 expression)

Mean Yes Yes

time to recurrence:

98

No

Yes (in comother mark- analysis, CD10 was an independent predictor of recurrence. Patients with low CD10 expression were more likely than those with high CD10 expression to develop recurrence (HR: 2.39, 95\% CI: 1.52-3.76, $P=0.001)$.

In the multivariate analysis, CD10 was an independent predictor of recurrence. Patients with recurrence were more likely than those without recurrence to exhibit strong stromal CD10 expression (OR: 10.2, 95\% CI: 2.7, 37.7).

In the multivariate analysis, SPARC was an independent predictor of recurrence. Patients with recurrence were more likely than those without recurrence to exhibit strong stromal SPARC expression (OR: 3.9, 95\% CI: 1.1, 14.3).

In the multivariate analysis, COX-2 was an independent predictor of recurrence. In addition, patients with recurrence were more likely than those without recurrence to have co-expression of COX-2 and cytoplasmic survivin compared to patients without recurrences co-expressing both proteins ( $70 \%$ vs. $41 \%$; $P=0.013)$.

COX-2 was not an independent predictor of recurrence. However, patients with recurrence were more likely than those without recurrence to express the combination of high Ki-67, high p16, and high COX-2 expression.

In the multivariate analysis, COX-2 expression was significantly associated with increased risk of recurrence (OR: 7.89; 95\% CI 1.7-36.2). bination with

In the univariate analysis, patients with invasive recurrence were more likely than those without recurrence to exhibit the phenotype $16^{+} \mathrm{COX}-2^{+} \mathrm{Ki}-67^{+}(23 \%$ vs. $8.5 \%)$. Patients with DCIS recurrence were more likely than those without a recurrence to exhibit the phenotype $16^{+} \mathrm{COX}-2-\mathrm{Ki}-67^{+}(19 \%$ vs. $2.6 \%)$. COX-2 was not individually associated with recurrence. In the multivariate analysis the phenotype $\mathrm{p} 16^{+} \mathrm{COX}-2^{+} \mathrm{Ki}-67^{+}$was a strong predictor of invasive recurrence (HR: 2.2; 95\% CI: 1.1-4.5). Another phenotype, p16 ${ }^{+} \mathrm{COX}-2-\mathrm{Ki}-67^{+}$, was a strong predictor of DCIS recurrence (HR: 3.7; 95\% CI: 1.7-7.9).

XRT, radiotherapy; VNPI, Van Nuys Prognostic Index. 